\title{
Physical Exercise Protects Against Alzheimer's Disease in 3xTg-AD Mice
}

\author{
Yoelvis García-Mesa ${ }^{\mathrm{a}}$, Juan Carlos López-Ramos ${ }^{\mathrm{b}}$, Lydia Giménez-Llort ${ }^{\mathrm{c}}$, Susana Revilla ${ }^{\mathrm{a}}$, \\ Rafael Guerra ${ }^{\mathrm{b}}$, Agnès Gruart ${ }^{\mathrm{b}}$, Frank M. LaFerla ${ }^{\mathrm{d}}$, Rosa Cristòfol ${ }^{\mathrm{a}}$, \\ José M. Delgado-García ${ }^{\mathrm{b}}$ and Coral Sanfeliu ${ }^{\mathrm{a}, *}$ \\ ${ }^{\mathrm{a}}$ Institute of Biomedical Research of Barcelona (IIBB), CSIC-IDIBAPS, Barcelona, Spain \\ ${ }^{\mathrm{b}}$ Division of Neurosciences, Universidad Pablo de Olavide, Sevilla, Spain \\ ${ }^{\mathrm{c}}$ Department of Psychiatry and Forensic Medicine, Institute of Neuroscience and Medical Psychology Unit, \\ Autonomous University of Barcelona, Bellaterra, Barcelona, Spain \\ ${ }^{\mathrm{d}}$ Department of Neurobiology and Behavior, University of California, Irvine, CA, USA
}

Handling Associate Editor: Gemma Casadesus

Accepted 13 December 2010

\begin{abstract}
Physical exercise is considered to exert a positive neurophysiological effect that helps to maintain normal brain activity in the elderly. Expectations that it could help to fight Alzheimer's disease (AD) were recently raised. This study analyzed the effects of different patterns of physical exercise on the 3xTg-AD mouse. Male and female 3xTg-AD mice at an early pathological stage (4-month-old) have had free access to a running wheel for 1 month, whereas mice at a moderate pathological stage (7-month-old) have had access either during 1 or 6 months. The non-transgenic mouse strain was used as a control. Parallel animal groups were housed in conventional conditions. Cognitive loss and behavioral and psychological symptoms of dementia (BPSD)-like behaviors were present in the 3xTg-AD mice along with alteration in synaptic function and long-term potentiation impairment in vivo. Brain tissue showed AD-pathology and oxidative-related changes. Disturbances were more severe at the older age tested. Oxidative stress was higher in males but other changes were similar or higher in females. Exercise treatment ameliorated cognitive deterioration and BPSD-like behaviors such as anxiety and the startle response. Synaptic changes were partially protected by exercise. Oxidative stress was reduced. The best neuroprotection was generally obtained after 6 months of exercise in 7-month-old 3xTg-AD mice. Improved sensorimotor function and brain tissue antioxidant defence were induced in both 3xTg-AD and NonTg mice. Therefore, the benefits of aerobic physical exercise on synapse, redox homeostasis, and general brain function demonstrated in the $3 \mathrm{xTg}$-AD mouse further support the value of this healthy life-style against neurodegeneration.
\end{abstract}

Keywords: 3xTg-AD mouse, age, Alzheimer's disease, amyloid- $\beta$, behavior, cognition, electrophysiology, gender, oxidative stress, PHF-tau, voluntary exercise

\section{INTRODUCTION}

Efforts are being made worldwide to uncover the basis of memory loss and other severe behavioral disturbances in Alzheimer's disease (AD) [1, 2]. Despite many years of intensive research, the mechanisms

\footnotetext{
*Correspondence to: Coral Sanfeliu, PhD, IIBB, CSICIDIBAPS, Rosselló 161, 6th Floor, 08036 Barcelona, Spain. Tel.: +3493 3638338; Fax: +34 93 3638301; E-mail: coral.sanfeliu@ iibb.csic.es.
}

triggering the disease remain uncertain and there is currently no cure [3-6]. Given the high prevalence of AD (around 100 million cases are estimated by year 2050), any intervention delaying its onset would significantly decrease the global burden [7]. Therefore, more attention is being paid to possible preventive and palliative therapies derived from a healthier lifestyle [8]. One such strategy is regular physical exercise. There is increasing awareness of the important health and psychological benefits elicited by regular physi- 
cal activity in the older population $[9,10]$. Its benefits may go beyond the normal aging process. Indeed, aerobic physical exercise is associated with a reduced incidence of $\mathrm{AD}$ in the at-risk population [11] and improved cognition in older adults at risk for $\mathrm{AD}$ [12]. These effects are gender-specific even though both men and women are responsive to training [13]. Physical exercise programs noticeably ameliorate mood [14] and symptoms of depression $[15,16]$ in AD patients. Therefore, physical exercise is a potential intervention to preserve or ameliorate cognitive function and behavior in AD. However, the mechanisms involved are poorly known and, therefore, the timing and duration of the exercise required to be effective against disease symptoms are uncertain.

Physical exercise may act through a number of pathways. Regular physical exercise can attenuate oxidative damage in the brain by reducing the production of reactive oxygen species (ROS) and stimulating the antioxidant systems [17, 18]. These effects indicate that exercise could be a preventive tool against neurodegeneration-associated oxidative challenge. Exercise can also improve brain metabolism and upregulate the expression of growth factors that regulate synaptic plasticity, neurogenesis, and angiogenesis, and can exert a direct effect on neural function [19, 20]. Some of the known molecular pathways involved are those of the growth factors brain-derived neurotrophic factor, insulin growth factor-1 and vascular endothelial growth factor, the mitogen-activated protein kinase and phosphatidylinositol 3-kinase signaling pathways, and the transcription factor cAMP response elementbinding (reviewed in [20]). Furthermore, physical exercise can change the function of glutamatergic systems, increasing both the NR2A and NR2B subtypes of the NMDA receptor in the hippocampus [21], which are crucial in learning and memory processes. Altogether, this indicates the great potential of exercise for overcoming AD neurodegenerative processes.

More studies are needed to understand the effects of exercise on $\mathrm{AD}$ neurodegeneration and to establish the optimum therapeutic programs. Transgenic mouse models of $\mathrm{AD}$ are useful and reliable experimental models for testing anti-AD therapies. The present study analyzed the effects of physical exercise using the AD triple transgenic mouse model (3xTg-AD) [22]. These mice develop age-dependent and progressive neuropathology that includes plaque and tangle pathology [23]. Their associated behavioral disturbances include cognitive (learning and memory impairments) and non-cognitive symptoms (behavioral and psy- chological symptoms of dementia, BPSD) and other neuronal symptoms that mimic AD dementia [24, 25]. In addition, these mice present a gender-related progression of AD changes [26, 27]. Therefore, 3xTg-AD is a valuable model for pre-clinical intervention studies. Previous studies with $3 \times \mathrm{Tg}$-AD showed some beneficial effects of physical exercise after 3 months in a freely available running wheel [28] or 1 month of forced exercise in a treadmill [29] in 6-monthold mice. The outcome of these previous was better cognitive improvement with voluntary exercise than with forced exercise, as reported for the $\mathrm{Tg} 2576 \mathrm{AD}$ mouse model in a comparative study using both exercise paradigms [30]. The aim of the present study was to evaluate the protective effect of voluntary exercise against $\mathrm{AD}$ pathology at early and moderate severity phases of the disease, in both sexes, using the $3 x T g-A D$ mouse model. Non-transgenic animals (NonTg) were included in the study as a reference. The effects of running wheel exercise were evaluated on: i) Physical function, by testing sensorimotor responses such as muscular strength, coordination and startle response/prepulse inhibition; ii) BPSD-like behavior, by testing exploration, curiosity, and anxiety responses; iii) Cognitive behavior, by means of spatial memory testing and instrumental conditioning; iv) Synaptic function status, by electrophysiological testing with a range of paired-pulse stimulations that induce paired excitatory post-synaptic potentials (EPSPs) and yield the input/output synaptic functions [31]; v) Long-term potentiation (LTP) evoked with high frequency stimulation (HFS) [32]; vi) AD pathology progression, by determining amyloid- $\beta(A \beta)$ and phospho-tau in the target brain areas; and vii) Oxidative stress in brain tissue, as a marker of both $\mathrm{AD}$ pathology progression and physical exercise effects on redox homeostasis. Notably, both paired-pulse stimulation and LTP were analyzed at the CA1medial prefrontal synapse in freely behaving mice [33]. This pathway has been reported to be involved in learning and memory processes and to express an inducible long-lasting NMDA-dependent form of LTP [34].

\section{MATERIALS AND METHODS}

\section{Animals}

The $3 \times$ Tg-AD mouse strain harboring the familial AD mutations PS1/M146V, AßPPSwe, and tauP301L were genetically engineered at the University of California Irvine [22]. Male and female 3xTg-AD mice 
from the Spanish colony of homozygous 3xTg-AD mice, established in the Medical Psychology Unit, Autonomous University of Barcelona [35], were used in the present study. The NonTg mouse colony had the same genetic background hybrid $(129 \times$ C57BL6) as $3 \times T g-A D$. Genotypes were confirmed by PCR analysis of DNA obtained from tail biopsies. Animals were maintained in Macrolon cages under standard laboratory conditions of food and water ad libitum, $22 \pm 2^{\circ} \mathrm{C}$ and $12 \mathrm{~h}$ light: dark. Estrous cycle of the female mice was not determined to avoid stressing the animals by the vaginal smear analyses. In addition, it is known that most female mice housed in groups in the same room spontaneously synchronize their estrous cycles [36]. This reduces the possibility of a hormone bias in the comparison of the different experimental groups.

Exercise treatment, general behavioral studies, and necropsies were performed in the facilities of the animal house of the University of Barcelona, under approval from the local animal ethics committee (CEEA, UB). Some experimental groups (see below: Experiment III) were transferred to the Universidad Pablo de Olavide, Sevilla, shortly before finishing their voluntary exercise regime and on arrival they were again housed with a running wheel until the end of the test. All studies were performed in accordance with Spanish legislation on the "Protection of Animals Used for Experimental and Other Scientific Purposes" and the European Communities Council Directive (86/609/EEC) on this subject.

\section{Administration of voluntary exercise}

Different patterns of administration of voluntary physical exercise in a running wheel followed by specific determinations were assayed in $3 \times \mathrm{Tg}-\mathrm{AD}$ and NonTg mice (Fig. 1A). Exercised animals were given free access to a running wheel. Four to five animals from different litters, grouped by genotype and gender, were housed in a cage with one running wheel (Activity Wheel Cage System for mice, Techniplast, Buguggiate, Italy). The system allowed continuous recording of the wheel turn number and therefore calculation of the average mouse running activity per cage (Fig. 1B). We chose to house the animals in groups to avoid the distress of individual housing. Periodic visual inspection suggested that all animals used the wheel, but it was not possible to quantify the running time of each mouse. Sedentary control mice were housed in similar cages without a running wheel.

\section{A Mouse age (months)}

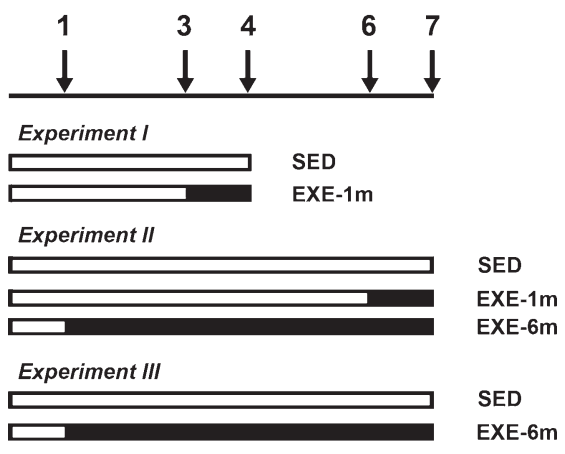

\section{B $\square$ NonTg EXE-1mo NonTg EXE-6mo $\square$ Tg EXE-1mo Tg EXE-6mo}

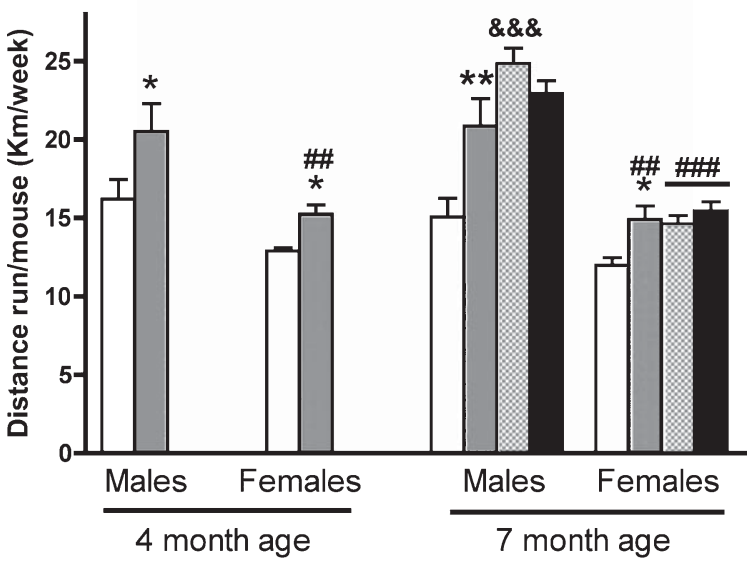

Fig. 1. The mouse model of Alzheimer's disease (AD) 3xTg-AD and its control strain (NonTg) were submitted to a treatment of voluntary physical execise with free access to a running wheel. Four-five mouse grouped by age and gender were housed in each cage with one wheel. A) Different exercise patterns were assayed; the filled bars indicate the period of access to the running wheel. Experiment I: Mice were allowed to exercise for 1 month between the ages of 3 and 4 months (EXE-1 mo) or were housed in standard conditions (SED); Experiment II: Male and female mice were allowed 1 month of running exercise at 6 months of age (EXE-1 mo), 6 months of exercise at 1 month of age (EXE-6 mo) or were housed in standard conditions (SED); Experiment III: Male mice from the EXE-6 mo group were selected for advanced studies of brain synaptic plasticity. B) The level of engagement in voluntary exercise of 3xTg-AD mice was higher than that of NonTg mice in the 1-month exercise treatment and similar in both strains in the 6-month exercise treatment. The distance run per mouse was calculated as the average of the distance covered by the 4-5 animals in each cage during the period of exercise treatment. Values are the mean \pm SEM. Statistics: Two-way ANOVA followed by Bonferroni's post hoc test. Significant differences between groups: $* p<0.05, * * p<0.01$ compared to the corresponding age and gender group of NonTg mice; $\#$ $p<0.01$, \#\#\# $p<0.001$ compared to the corresponding genotype group of male mice; ${ }^{\& \& \&} p<0.001$ compared to the corresponding group exercised 1 month. 


\section{Experiment I: One month of exercise, ending at 4 months of age}

Three-month-old male and female $3 \times \mathrm{Tg}-\mathrm{AD}$ and NonTg mice were given free access to a running wheel for 1 month. Two cages were used per experimental treatment (8-10 mice/experimental EXE group). Sedentary male and female $3 x \mathrm{Tg}-\mathrm{AD}$ and NonTg mice were also used in the experiment (8-10 mice/experimental SED group).

\section{Experiment II: One/six months of exercise, ending at 7 months of age}

Male and female 3xTg-AD and NonTg mice were given 1-month (EXE-1 mo group) or 6-month (EXE-6 mo group) free access to a running wheel starting when they were 6-month-old or 1-monthold, respectively. The corresponding sedentary groups were housed accordingly (SED-1 mo and SED-6 mo groups). Eight to ten mice were allocated to each experimental group. The general physical and behavioral profile (non-cognitive and cognitive), brain pathology, brain amyloid levels, and oxidative stress status of the mice were analyzed in Experiment I and II.

\section{Experiment III: Six months of exercise, ending at 7 months of age}

Mice subjected to the 6-month wheel running treatment (3xTg-AD EXE) were selected for electrophysiological analyses of brain synaptic function and plasticity as this regime had the best outcome. Therefore, new experimental groups of 7-month-old male $3 \times \mathrm{Tg}-\mathrm{AD}$ mice in the sedentary $(3 \mathrm{xTg}-\mathrm{AD})$ or 6-months of exercise condition (3xTg-AD EXE) and a control sedentary NonTg group (NonTg) were submitted to brain surgery as detailed below. Upon completion of these studies, specific behavioral testing to further check their sensorimotor and cognitive capacities were performed. This completed the profile of exercised and sedentary $3 \mathrm{xTg}-\mathrm{AD}$ mice using de novo assays in this mouse model.

\section{Physical and behavioral profile of $3 x T g-A D$ mice after exercise}

At termination of the exercise period in Experiments I and II, the mice were moved to cages without a wheel. The physical condition, behavior, and cognition [24, 29] of both EXE and SED mice were evaluated. Where indicated, behavioral testing was performed in animals allocated to Experiment III instead.

\section{Body weight and sensorimotor functions}

The physical condition of the mice was evaluated by measuring their body weight, including the contribution of intra-abdominal white adipose tissue (WAT), and their sensorimotor responses to a standardized task battery. Reflexes (visual reflex and posterior legs extension reflex tests) were measured three times by holding the animal by its tail and slowly lowering it towards a black surface. Motor coordination and equilibrium were assessed by the distance covered and the latency to fall off a horizontal wooden rod $(1.3 \mathrm{~cm}$ wide) on two consecutive 20 -s trials, respectively. In order to increase the difficulty of the task, the test was repeated on a metal wire rod ( $1 \mathrm{~cm}$ diameter). Prehensility and motor coordination were measured as the distance covered on the wire hang test, which consisted of allowing the animal to cling from the middle of a horizontal wire (diameter: $2 \mathrm{~mm}$, length: $40 \mathrm{~cm}$, divided into eight 5 -cm segments) with its forepaws for two trials of $5 \mathrm{~s}$ and a third 60-s trial. Muscle strength was measured as the time taken to fall off the wire in the 60-s trial. All the apparatus were suspended $80 \mathrm{~cm}$ above a padded table.

\section{Corner test}

Neophobia to a new home-cage was assessed by introducing the animal into the center of a standard square cage (Macrolon, $35 \times 35 \times 25 \mathrm{~cm}$ ) and counting the number of corners visited and rearings during a period of $30 \mathrm{~s}$. The latency of the first rearing was also recorded.

\section{Open field test}

Mice were placed in the center of the apparatus (home-made, wooden, white, $55 \times 55 \times 25 \mathrm{~cm}$ high) and observed for $5 \mathrm{~min}$. Horizontal (crossings of $5 \times 5 \mathrm{~cm}$ squares) and vertical (rearings) locomotor activity was recorded for each minute of the test. We also recorded the latency of the sequence of the following behavioral events: initial freezing (latency of initial movement), thigmotaxis, or discrimination of unprotected/protected areas in the test (latency of leaving the central $5 \times 5 \mathrm{~cm}$ square, and that of entering the peripheral ring $5 \mathrm{~cm}$ from the walls), and selfgrooming behavior (latency, number and duration of grooming episodes). The number of defecation boli was also recorded.

\section{Dark and light box test}

Anxiety-like behavior was also measured in a dark-light box (Panlab, S.L., Barcelona, Spain). The apparatus consisted of two compartments (black, 
$27 \times 18 \times 27 \mathrm{~cm}$, white $27 \times 27 \times 27 \mathrm{~cm}$, lit with a $20 \mathrm{~W}$ white bulb) connected by an opening $(7 \times 7 \mathrm{~cm})$. The mice were introduced into the black compartment and observed for $5 \mathrm{~min}$. The latency to enter (all four paws) the lit compartment, the time spent in the lit compartment and the horizontal (crossings of $3 \times 3 \mathrm{~cm}$ ) and vertical (rearings) activity that took place once there, were recorded. The number of defecation boli was also recorded.

\section{Boissier's four hole-board test}

Exploratory behavior was measured as the number of head-dips and time spent head-dipping on each of the four holes $(3 \mathrm{~cm}$ diameter) equally spaced in the floor of the hole-board (woodwork white box of $32 \times 32 \times 32 \mathrm{~cm}$ ). The latencies of movement, first dipping and four hole dipping, and number of defecation boli were also recorded.

\section{Morris water maze (MWM) tests}

Animals were tested for spatial learning and memory in the MWM [37] consisting of one day of cue learning and six days of place learning for spatial reference memory, followed by one probe trial. Mice were trained to locate a platform $(7 \mathrm{~cm}$ diameter, $1.5 \mathrm{~cm}$ below the water surface) in a circular pool ( $91 \mathrm{~cm}$ diameter, $40 \mathrm{~cm}$ height, $25^{\circ} \mathrm{C}$ opaque water, surrounded by black curtains) by relying on visual cues. Within the black enclosure, four different landmarks were hung from a false black ceiling at $90^{\circ}$ to each other. The platform was placed between two of these landmarks. The landmarks and the platform were semi-randomly rotated with respect to the $\operatorname{room}\left(90^{\circ}, 180^{\circ}, 270^{\circ}, 360^{\circ}\right)$ in a daily-balanced way in order to ensure that the animal used these landmarks, rather than any inadvertently remaining static room cue, to locate the platform [38].

On the first day, the animals were tested for the cue learning of a visual platform consisting of five trials in one day. In each trial, the mouse was gently released (facing the wall) from one randomly selected starting point (N, S, E, or $\mathrm{W}$ ) and allowed to swim until it escaped onto the platform (starting NW for the first trial). The position of the platform was indicated by a visible striped flag $(5 \times 8 \mathrm{~cm})$. On the following day, the place learning task consisted of five trial sessions per day for 6 days, with trials spaced 15 min apart. Mice that failed to find the platform within $60 \mathrm{~s}$ were placed on it for $10 \mathrm{~s}$, the same period as was allowed for the successful animals. On day 7, after one trial of place learning, the platform was removed from the maze and the mice performed a probe trial test of $60 \mathrm{~s}$. A computerized tracking system (SMART, Panlab S.A., Barcelona, Spain) allowed the escape latency during the learning tasks to be measured, along with the time spent in each quadrant of the pool after the removal of the platform in the probe trial test.

\section{Startle response and prepulse inhibition task}

Selected treatment groups (those of Experiment III) were analyzed for prepulse inhibition of the startle response to further check the functional sensorimotor changes after 6 months of physical exercise treatment. The different parameters of the startle reflex and the prepulse inhibition tests were assessed in $n=11$ NonTg, $n=123 \mathrm{xTg}-\mathrm{AD}$, and $n=103 \times \mathrm{Tg}-\mathrm{AD}$ EXE mice. Animals were placed individually inside a startle chamber (Cibertec S.A., Madrid, Spain). The startle response was measured using a piezoelectric accelerometer controlled by a computer, using a previously described protocol $[39,40]$. The digitized signal was averaged from 25 to 30 recordings. For training, the mouse was placed in the startle chamber for an acclimation period of $3 \mathrm{~min}$. Baseline responses were averaged after the presentation of 20 sounds $(125 \mathrm{~dB}$, $100 \mathrm{~ms}$ long). During prepulse inhibition trials, the same $125-\mathrm{dB} 100-\mathrm{ms}$ burst was preceded $(250 \mathrm{~ms})$ by a prepulse stimulus of $85 \mathrm{~dB}$, lasting for $50 \mathrm{~ms}$. Trials including prepulse stimuli were randomly presented with normal startle stimuli, the final total being 25 of each. The ambient background noise was $70 \mathrm{~dB}$. Data were recorded using the Morns computer program (Cibertec S.A. Madrid, Spain) and stored for off-line processing. Four different indices of startle response and prepulse inhibition, related to the response latency, the maximum peak latency, the maximum peak value, and the total response area were recorded and quantified [41]. These indices of prepulse inhibition were obtained by computing the following formula: [(startle/prepulse ratio $) \times 100] /$ baseline value. Statistical analysis was performed using the SPSS program.

\section{Instrumental conditioning}

The 6-month exercise treatment was also analyzed for its effects on the acquisition of instrumental (operant) conditioning behavior (mouse groups in Experiment III). A total of 17 NonTg, $93 x T g-A D$, and 8 3xTg-AD EXE male animals were selected for the operant conditioning task. Training and testing took place in standard Skinner box modules $(n=3)$ measuring $12.5 \times 13.5 \times 18.5 \mathrm{~cm}$ (MED Associates, St. Albans, VT, USA). The operant chambers were housed within a sound-attenuating chamber 
$(90 \times 55 \times 60 \mathrm{~cm})$, which was constantly illuminated (19 W lamp) and exposed to a $45 \mathrm{~dB}$ white noise (Cibertec, S.A., Madrid, Spain). Each Skinner box was equipped with a food dispenser from which pellets (Noyes formula P; $20 \mathrm{mg}$; Sandown Scientific, Hampton, UK) could be obtained by pressing a lever. Before the task, mice were handled daily for 7 days and food-deprived, weighing them daily until reaching $80 \%$ of their free-feeding weight and remaining with this daily use until the end of the experiment. Conditioning took place for $20 \mathrm{~min}$ on successive days, in which mice were trained to press the lever to receive pellets from the food tray using a fixed-ratio $(1: 1)$ schedule. Animals were maintained on this $1: 1$ schedule until they reached the selected criterion - namely, until they were able to obtain $\geq 20$ pellets for two successive sessions, or after 5 days of training (for details see [40]). Cumulative records of lever pressing and pellet rewards were stored on-line on a computer connected to the Skinner boxes, and the results were processed for statistical analysis using the SPSS program.

\section{Brain neurophysiological responses in $3 x T g-A D$ mice after exercise}

Upon termination of the exercise period in Experiment III, all mice were submitted to brain surgery for electrode implants to analyze field EPSPs in pairedpulse stimulations and LTP induction. After recovery from surgery and electrophysiological testing, animals were maintained in cages with a running wheel until they were submitted to additional behavioral testing (see above).

\section{Surgical procedures}

Under deep anesthesia (Ketamine, $35 \mathrm{mg} / \mathrm{kg}$ and Xylazine, $2 \mathrm{mg} / \mathrm{kg}$, i.p.), animals were implanted with bipolar stimulating electrodes aimed at the right CA1 area of the dorsal hippocampus $(2.75 \mathrm{~mm}$ lateral and $3.16 \mathrm{~mm}$ posterior to the Bregma; depth from brain surface, $2.0-2.25 \mathrm{~mm}$ [43]) and with a recording electrode aimed at the right infralimbic area of the medial prefrontal cortex $(0.3 \mathrm{~mm}$ lateral and $1.94 \mathrm{~mm}$ anterior to the Bregma; depth from brain surface, 3-3.3 mm). These electrodes were made of $50 \mu \mathrm{m}$ diameter, Teflon-coated tungsten wire (Advent Research Materials Ltd., Eynsham, England). Injection of retrograde tracers (aminostilbamidine methanesulfonate, Sigma) in the prefrontal area (Fig. 2A, arrow) indicated the best position for the stimulating electrode (Fig. 2B, arrow) in the CA1 area. The final position of the medial prefrontal recording electrodes (Fig. 2C) was determined using as a guide the field potential depth profile evoked by paired (100-ms interval) pulses presented
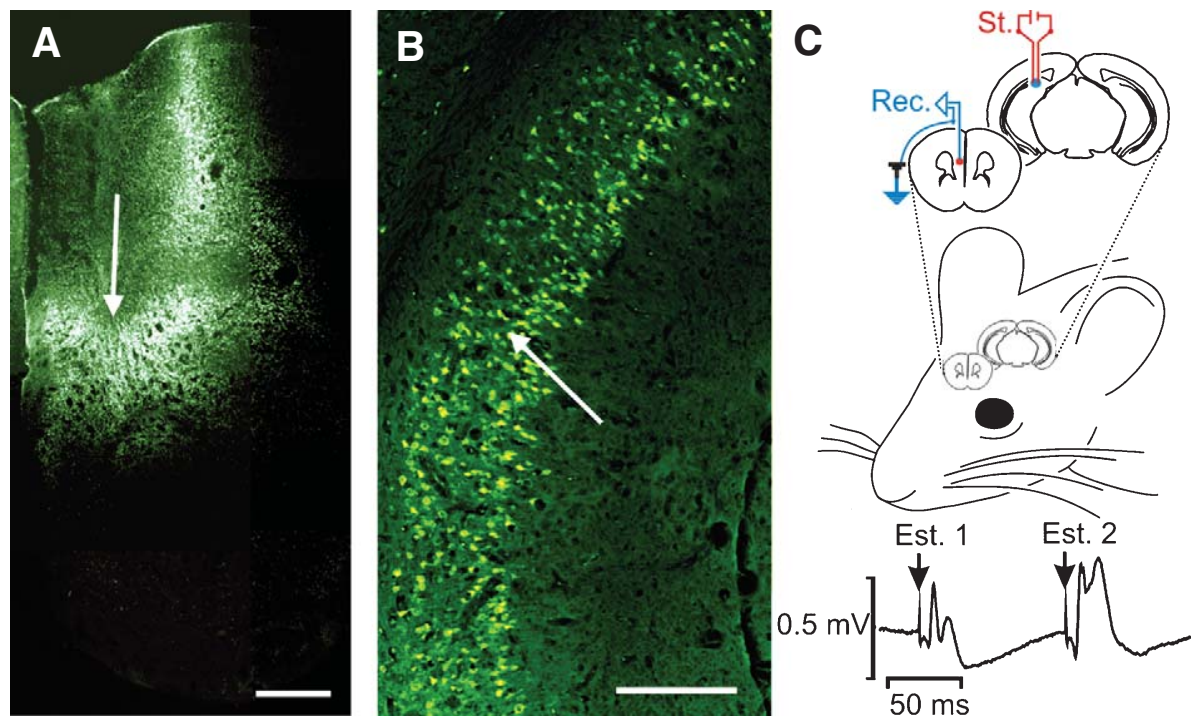

Fig. 2. Experimental design for electrophysiological studies of synaptic plasticity. A) Photomicrograph showing the position (arrow) of the retrograde tracer injection in the prefrontal cortex, to check the best electrode position. B) Result of tracer migration to the CA1 (arrow). C) Animals were implanted with recording (Rec.) electrodes in the right infralimbic area of the medial prefrontal cortex, and with stimulating (St.) electrodes at the point in the hippocampal CA1 area at which the most tracer-marked cells were observed. A representative record (averaged ten times) illustrating the field EPSP recorded in the medial prefrontal cortex following electrical stimulation of the hippocampal CA1 area is shown at the bottom. Calibration bar $=500 \mu \mathrm{m}$. 
at the ipsilateral CA1 area (Fig. 2C, bottom). Thus, the recording electrode was fixed at the site at which a reliable monosynaptic field EPSP was recorded.

A $0.1-\mathrm{mm}$ bare silver wire was affixed to the skull as an earth. Wires were connected to one four-pin socket (RS-Amidata, Madrid, Spain). The sockets were fixed to the skull with the help of two small screws and dental cement $[44,45]$. After surgery, animals were kept in individual cages, with free access to food and water, for the rest of the experiment. Recording sessions started one week after surgery.

\section{Recording and stimulating procedures}

During recording sessions, animals were placed individually in a plastic chamber $(5 \mathrm{~cm} \times 15 \mathrm{~cm} \times$ $15 \mathrm{~cm})$, located inside a larger Faraday box $(30 \mathrm{~cm} \times$ $30 \mathrm{~cm} \times 20 \mathrm{~cm})$ to eliminate electrical interference. Field EPSP recordings were carried out using Grass P511 differential amplifiers with the help of a highimpedance probe $\left(2 \times 10^{12} \Omega, 10 \mathrm{pF}\right)$. Commercial computer programs (Signal 3, from CED) were configured to represent the EMG and field EPSP recordings. Data were analyzed off-line for quantification of field EPSP amplitudes. For input/output curves, animals ( $n=5$ per group) were stimulated at the CA1 area with paired pulses at different inter-stimulus intervals $(10,20,40,100,200$, and $500 \mathrm{~ms})$, and at increasing intensities (0.3-4.8 mA). In all cases, the pair of pulses of a given intensity were repeated $\geq 5$ times at intervals $\geq 30 \mathrm{~s}$, to avoid as much interference as possible with slower short-term potentiation (augmentation) or depression processes [46]. Moreover, to avoid any cumulative effect, the different intensities and intervals were presented at random [31]. To detect significative differences, one-way ANOVA was carried out using the SPSS software.

\section{LTP induction}

To evoke LTP, animals ( $n=8$ NonTg, $n=73 x$ Tg$\mathrm{AD}$; and $n=83 \mathrm{xTg}$-AD EXE mice) were presented with an HFS protocol consisting of five $200-\mathrm{Hz}$, 100-ms trains of pulses at a rate of $1 / \mathrm{s}$. This HFS protocol was presented six times in total, at intervals of $1 \mathrm{~min}$. The $50-\mu \mathrm{s}$, square, biphasic pulses used to evoke LTP were applied at intensities ranging from 0.6 to $1.2 \mathrm{~mA}$. For each animal, the stimulus intensity was set well below the threshold for evoking a population spike, usually $30-40 \%$ of the intensity necessary to evoke a maximum field EPSP response [45, 47]. An additional criterion for selecting the stimulus intensity was that a second stimulus, presented $100 \mathrm{~ms}$ after a conditioning pulse, evoked a larger (>20\%) synaptic field potential than the first one [48].

Prior to the HFS session, baseline field EPSP records, evoked by pairs of pulses spaced $100 \mathrm{~ms}$ apart, were recorded for $15 \mathrm{~min}$ at a rate of $1 / 20 \mathrm{~s}$. After HFS, field EPSP records were continued for $60 \mathrm{~min}$. Field EPSPs were recorded for $15 \mathrm{~min}$ for two additional days following the HFS session. Field EPSP recordings were carried out as described elsewhere [31, 45] and statistical analysis was carried out using the SPSS program.

\section{Body weight and brain tissue samples}

The body weight in the different experimental groups from Experiments I and II was recorded initially and at the beginning and end of the exercise period to check the effect of each exercise treatment. Upon termination, the contribution of intra-abdominal WAT to total body weight was calculated as the percentage of weight of dissected WAT versus the total body weight.

The hippocampi and cerebral cortices were quickly dissected on ice and stored at $-80^{\circ} \mathrm{C}$ for further analysis of amyloid levels and oxidative stress parameters (see below). Samples to be used for immunohistochemistry were immediately processed as described in the next section.

\section{Immunohistochemistry}

The hemibrain of four animals per group from Experiments I and II was fixed by immersion in $4 \%$ paraformaldehyde for $48 \mathrm{~h}$. Paraffin-embedded brain sections were cut at $8 \mu \mathrm{m}$. Sections were autoclaved in citrate buffer $\mathrm{pH} 6$ for $10 \mathrm{~min}$ to expose the epitopes. The endogenous peroxidase activity was quenched for 15 min in $1 \% \mathrm{H}_{2} \mathrm{O}_{2}$. Sections were immunostained with anti-A $\beta$ (clone 4G8, Covance, Emervylle, CA, USA) or anti-phospho-tau (clone AT180, Thermo Scientific, Rockford, IL). Anti-A $\beta$ clone 4G8 is highly reactive to amino acid residues $17-24$ of human $A \beta$, but it also reacts to the precursor form. Anti-tau clone AT180 recognizes human PHF-tau and tangles and cross-reacts weakly with normal tau. Incubations were performed overnight at $4{ }^{\circ} \mathrm{C}$ at the dilutions of $1: 50$ and $1: 100$ for $A \beta$ and PHF-tau antibodies, respectively. After subsequent washes to remove primary antibody excess, sections were incubated with the appropriate biotin-conjugate secondary antibody for $1 \mathrm{~h}$ at room temperature. Signal was amplified using the avidinbiotin horseradish peroxidase system following the manufacturer's instructions (Vectastain ABC kit, Vec- 
tor Laboratories, Inc.). Then, peroxidase reaction was developed with diaminobenzidine and hydrogen peroxide. Sections were dehydrated and mounted with dextropropoxyphene (DPX, Fluka).

\section{Amyloid- $\beta$ ELISA}

Amyloid levels were analyzed in hippocampal tissue. Soluble $A \beta_{40}$ and $A \beta_{42}$ were determined using commercial ELISA kits (KHB348 and KHB344, respectively, Invitrogen, Camarillo, CA), following the manufacturer's instructions. Samples were measured at $320 \mathrm{~nm}$ using a plate reader (iEMS Reader MF; Labsystems, Vantaa, Finland). Fibrillar aggregates of $A \beta_{40}$ and $A \beta_{42}$ were expected to be negligible at the pathological stages assayed and so were not tested [26].

\section{Lipid peroxidation, glutathione peroxidase, and superoxide dismutase assays}

For lipid peroxidation and enzymatic assays, $100 \mathrm{mg}$ of cerebral cortex tissue was sonicated for $30 \mathrm{~s}$ in $1 \mathrm{ml}$ of ice-cold $50 \mathrm{mM}$ potassium phosphate buffer containing $1 \mathrm{mM}$ EDTA pH 7.4 and were then centrifuged at $12,000 \times g$ for $30 \mathrm{~min}$ at $4^{\circ} \mathrm{C}$. The supernatants were collected and stored at $-80^{\circ} \mathrm{C}$ until assay. Enzymatic activities and lipid peroxidation were determined as described previously [49]. Lipid peroxidation was measured by determining malondialdehyde and 4-hydroxyalkenal (MDA + 4-HAD) using a Lipid Peroxidation Assay Kit from Calbiochem (EMD Biosciences Inc., Darmstadt, Germany). Glutathione peroxidase (GPx) activity was determined by measuring spectrophotometrically the rate of $\beta$-nicotinamide adenine dinucleotide phosphate (NADPH) oxidation in the presence of hydrogen peroxide. Superoxide dismutase (SOD) activity was measured using the SOD assay kit Ransod (Randox Laboratories Ltd, Crumlin, UK), based on the xanthine/xanthine oxidase system. After total SOD (Cu/Zn SOD and Mn SOD) was determined, samples were again analyzed in the presence of $500 \mu \mathrm{M} \mathrm{KCN}$ to inhibit CuZn SOD and to determine Mn SOD activity. SOD CuZn activity was calculated by subtracting Mn SOD activity. Proteins were measured in $10 \mu \mathrm{l}$ of supernatants following the Bradford method.

\section{Reduced glutathione and oxidized glutathione assays}

For reduced glutathione (GSH) and oxidized glutathione disulfide (GSSG) assays, $200 \mathrm{mg}$ of cerebral cortical tissue was sonicated in $1 \mathrm{ml}$ of $3.3 \%$ sulfos- alicylic acid. Acid homogenates were centrifuged at $12,000 \times \mathrm{g}$ for $30 \mathrm{~min}$ at $4{ }^{\circ} \mathrm{C}$ and supernatant fractions were collected and stored at $-80^{\circ} \mathrm{C}$ until assay. The levels of GSH and GSSG were determined using an enzymatic assay [50] that is essentially a modification of Tietze's recycling method. Samples for GSSG determination were previously incubated at room temperature with $2 \mu \mathrm{l}$ of 2 -vinyl pyridine per $100 \mu \mathrm{l}$ sample in order to conjugate any GSH present in the sample, such that only GSSG was recycled to GSH. Both GSH and GSSG samples were then neutralized by the addition of $6 \mu \mathrm{l}$ of triethanolamine. For total glutathione determination, $50 \mu \mathrm{l}$ of each sample was mixed with $100 \mu \mathrm{l}$ of $100 \mathrm{mM}$ sodium phosphate/1 mM EDTA buffer containing $1 \mathrm{mM}$ dithiobisnitrobenzoate, $20 \mathrm{U} / \mathrm{ml}$ glutathione reductase, and $1 \mathrm{mM}$ NADPH. The kinetics of the formation of 5-thio-2-nitrobenzoic acid was immediately recorded at $30^{\circ} \mathrm{C}$ and $405 \mathrm{~nm}$, every $15 \mathrm{~s}$ over a 5-min period.

\section{Statistics}

Results were expressed as mean \pm SEM. One-way or two-way ANOVA followed by post hoc Bonferroni, Newman-Keuls, or Dunnett tests were performed using GraphPad Prism 4 software. Temporal courses were analyzed using repeated-measures ANOVA. SPSS software was used where indicated.

\section{RESULTS}

\section{Short-term voluntary running activity is higher} in 3xTg-AD than NonTg mice

The average running distance per mouse for each cage was calculated from the total counts for each wheel per week (Fig. 1B). Two-way ANOVA showed an effect of 'genotype' and 'gender' for both, 4-month-old mice $\left[\mathrm{F}_{(1,36)}=17.18, p=0.0002\right.$, and $\mathrm{F}_{(1,36)}=28.44, p<0.0001$, for 'genotype' and 'gender', respectively $]$ and 7-month-old mice $\left[\mathrm{F}_{(1,70)}=\right.$ $6.95, p=0.0103$, and $\mathrm{F}_{(1,70)}=84.68, p<0.0001$, for both factors, respectively]. Both male and female 3xTg-AD mice exposed to exercise for 1 month showed a higher level of engagement in the running activity than their NonTg counterparts. In addition, male $3 \times \mathrm{Tg}-\mathrm{AD}$ mice were more active than female mice, whereas this gender difference was not significant in NonTg mice. Similar running distances were attained for each gender and genotype at both ages tested (4 months and 7 months) after 1 month of 
Table 1A

Physical exercise exerted beneficial effects on the sensorimotor function in 4-month-old NonTg and 3xTg-AD male mice

\begin{tabular}{|c|c|c|c|c|}
\hline & $\begin{array}{c}\text { NonTg SED } \\
\quad(n=10)\end{array}$ & $\begin{array}{c}\text { NonTg EXE-1 mo } \\
(n=10)\end{array}$ & $\begin{array}{l}\text { Tg SED } \\
(n=10)\end{array}$ & $\begin{array}{c}\text { Tg EXE-1 mo } \\
(n=10)\end{array}$ \\
\hline \multicolumn{5}{|l|}{ Body weight } \\
\hline \multicolumn{5}{|l|}{ Weight curve } \\
\hline Week 1 (g) & $21.1 \pm 0.3$ & $21.1 \pm 0.5$ & $24.6 \pm 0.8 *$ & $24.3 \pm 0.8 *$ \\
\hline Week $5(\mathrm{~g})$ & $23.6 \pm 0.3$ & $21.2 \pm 2.3$ & $27.5 \pm 0.5^{* *}$ & $27.5 \pm 0.6^{* *}$ \\
\hline WAT ( $\%$ vs body weight) & $1.0 \pm 0.1$ & $0.8 \pm 0.1$ & $1.2 \pm 0.1$ & $1.1 \pm 0.1$ \\
\hline \multicolumn{5}{|l|}{ Sensorimotor function } \\
\hline \multicolumn{5}{|l|}{ Reflex tests } \\
\hline Incidence of both reflexes & $10 / 10$ & $9 / 10$ & $10 / 10$ & $10 / 10$ \\
\hline \multicolumn{5}{|l|}{ Wooden rod test } \\
\hline Equilibrium (mean latency to fall, s) & $17.8 \pm 0.1$ & $18.7 \pm 0.6$ & $19.2 \pm 0.4^{*}$ & $20.0 \pm 0.0^{*}$ \\
\hline Coordination (mean distance, $\mathrm{cm}$ ) & $0.3 \pm 0.1$ & $2.1 \pm 0.2^{\# \# \#}$ & $0.6 \pm 0.1$ & $5.4 \pm 0.1 * * *, \# \# \#$ \\
\hline \multicolumn{5}{|l|}{ Wire rod test } \\
\hline Equilibrium (mean latency to fall, s) & $3.2 \pm 0.3$ & $8.4 \pm 1.8$ & $7.0 \pm 1.8$ & $14.8 \pm 3.0^{*, \#}$ \\
\hline Coordination (mean distance, $\mathrm{cm}$ ) & $0 \pm 0$ & $0.8 \pm 0.0^{\# \# \#}$ & $0.1 \pm 0.0 * * *$ & 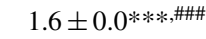 \\
\hline \multicolumn{5}{|l|}{ Wire hang test ( 2 trials $5 \mathrm{~s})$} \\
\hline Strength (mean latency to fall, s) & $3.6 \pm 0.0$ & $3.9 \pm 0.1^{\#}$ & $4.4 \pm 0.1 * * *$ & $4.5 \pm 0.0 * * *$ \\
\hline Coordination (mean distance, $\mathrm{cm}$ ) & $0.5 \pm 0.0$ & $0.9 \pm 0.0^{\# \#}$ & $1.5 \pm 0.2 * * *$ & $0.8 \pm 0.1 *$,\#\# \\
\hline Elements of support $(n)$ & $1.5 \pm 0.0$ & $1.5 \pm 0.0$ & $2.1 \pm 0.0 * * *$ & $2.1 \pm 0.1 * * *$ \\
\hline \multicolumn{5}{|l|}{ Wire hang test ( 1 trial $60 \mathrm{~s})$} \\
\hline Strength (mean latency to fall, s) & $21.0 \pm 7.2$ & $15.8 \pm 5.8$ & $50.3 \pm 6.7 *$ & $48.3 \pm 6.1^{* *}$ \\
\hline Coordination (mean distance, $\mathrm{cm}$ ) & $1.8 \pm 0.8$ & $1.2 \pm 0.5$ & $2.9 \pm 0.6$ & $3.6 \pm 0.8$ \\
\hline Elements of support $(n)$ & $2.0 \pm 0.4$ & $2.0 \pm 0.4$ & $2.4 \pm 0.4$ & $2.7 \pm 0.3$ \\
\hline
\end{tabular}

Note: NonTg SED and Tg SED, non transgenic and 3xTg-AD male mice housed in standard conditions; NonTg EXE-1 mo and Tg EXE-1 mo, non transgenic and 3xTg-AD male mice allowed free access to a running wheel during 1 month (week 1 to week 5 of the study) at 3 months of age. Results are the mean \pm SEM. Significant (Newman-Keuls post hoc test) differences between groups: ${ }^{*} p<0.05,{ }^{* *} p<0.01,{ }^{* * *} p<0.001$ compared to the corresponding NonTg mice; ${ }^{\#} p<0.05,{ }^{\# \#} p<0.01,{ }^{\# \# \#} p<0.001$ compared to corresponding SED mice.

exercise treatment. In the longer exercise treatment of 6 months, NonTg mice increased their running activity up to the level of the 3xTg-AD mice.

\section{Physical exercise exerted beneficial effects on the physical and behavioral profile of $3 x T g-A D$ mice}

\section{Exercise reduced body weight}

Mouse body weight is shown in Tables 1A-D. Before exercise training, male $3 \mathrm{xTg}-\mathrm{AD}$ mice had a higher body weight than NonTg mice and this difference was maintained during 1-month exercise treatment, both in 4-month-old (Table 1A) and 7month-old mice (Table 1C). One month of physical exercise reduced the weight of 7-month-old female 3xTg-AD mice (Table 1D) and of both gender of NonTg mice (Tables 1C, D). Six months of exercise decreased body weight in all animal groups, lowered the weight of $3 \times \mathrm{Tg}-\mathrm{AD}$ mice to that of NonTg mice (Tables 1C, D). Two-way ANOVA indicated an effect of 'genotype' in males at the first week of the study $\left[\mathrm{F}_{(1,36)}=26.53, p<0.0001\right.$, in 4-month-old mice and $\mathrm{F}_{(1,66)}=23.27, p<0.0001$ in 7-month-old mice $]$ and at the last week $\left[\mathrm{F}_{(1,36)}=17.15, p=0.0002\right.$, and $F_{(1,66)}=21.84, p<0.0001$, for both mouse ages, respectively], but not in females. The factor 'exer- cise' was significant in both genders of 7-month-old mice $\left[\mathrm{F}_{(2,66)}=4.68, p=0.0125\right.$, and $\mathrm{F}_{(2,63)}=15.76$, $p<0.0001$, for males and females, respectively]. Exercise led to a tendency for a reduced percentage of WAT in all groups that was only significant in 7-month-old female mice (Table 1D) [ANOVA, factor 'exercise': $\left.\mathrm{F}_{(2,63)}=4.67, p=0.0128\right]$.

\section{Exercise improved sensorimotor task}

At 4 months of age, male and female $3 x \mathrm{Tg}$-AD mice showed better sensorimotor responses than NonTg mice, both in muscular strength, equilibrium, and coordination. Physical training in the running wheel improved general sensorimotor function in NonTg mice and further increased coordination in $3 \times \mathrm{Tg}-\mathrm{AD}$ mice (Table 3)(Tables 1A, B). Two-way ANOVA indicated an effect of factor 'genotype' in the rod tests and most hang tests [not significant: coordination and elements of support in the wire hang test $1 \times 60 \mathrm{~s}$ in males, coordination in the same test in females; all others: $\left.\mathrm{F}_{(1,36)}>11.41, p<0.0018\right]$ and an effect of factor 'exercise' in the rod tests [all F's ${ }_{(1,36)}>4.34, p<0.0444$ ] in both, male and female 4-month-old mice. At 7 months of age, 3xTg-AD mice still had better sensorimotor function than NonTg mice mainly shown by better wooden rod balance in males (Table 1C) and higher 
Table 1B

Physical exercise exerted beneficial effects on the sensorimotor function in 4-month-old NonTg and 3xTg-AD female mice

\begin{tabular}{|c|c|c|c|c|}
\hline & $\begin{array}{l}\text { NonTg SED } \\
\quad(n=10)\end{array}$ & $\begin{array}{c}\text { NonTg EXE-1 mo } \\
\quad(n=10)\end{array}$ & $\begin{array}{l}\text { Tg SED } \\
(n=10)\end{array}$ & $\begin{array}{l}\text { Tg EXE-1 mo } \\
(n=10)\end{array}$ \\
\hline \multicolumn{5}{|l|}{ Body weight } \\
\hline \multicolumn{5}{|l|}{ Weight curve } \\
\hline Week 1 (g) & $18.0 \pm 0.3$ & $17.7 \pm 0.5$ & $19.4 \pm 0.9$ & $19.2 \pm 0.4$ \\
\hline Week $5(\mathrm{~g})$ & $20.0 \pm 0.3$ & $20.4 \pm 0.5$ & $21.5 \pm 0.8$ & $21.3 \pm 0.6$ \\
\hline WAT (\% vs body weight) & $0.7 \pm 0.1$ & $0.9 \pm 0.3$ & $1.1 \pm 0.2$ & $0.8 \pm 0.1$ \\
\hline \multicolumn{5}{|l|}{ Sensorimotor function } \\
\hline \multicolumn{5}{|l|}{ Reflex tests } \\
\hline Incidence of both reflexes & $9 / 10$ & $10 / 10$ & $9 / 10$ & $10 / 10$ \\
\hline \multicolumn{5}{|l|}{ Wooden rod test } \\
\hline Equilibrium (mean latency to fall, s) & $17.6 \pm 0.2$ & $18.9 \pm 0.5^{\#}$ & $19.1 \pm 0.4^{*}$ & $20.0 \pm 0.0$ \\
\hline Coordination (mean distance, $\mathrm{cm}$ ) & $0.2 \pm 0.0$ & $1.6 \pm 0.1^{\# \# \#}$ & $1.7 \pm 0.1 * * *$ & 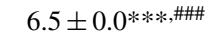 \\
\hline \multicolumn{5}{|l|}{ Wire rod test } \\
\hline Equilibrium (mean latency to fall, s) & $4.5 \pm 1.1$ & $8.3 \pm 1.1$ & $12.8 \pm 2.2^{*}$ & $17.9 \pm 3.2 * *$ \\
\hline Coordination (mean distance, $\mathrm{cm}$ ) & $0 \pm 0$ & $0 \pm 0$ & $0.6 \pm 0.0 * * *$ & $1.5 \pm 0.2 * * *, \# \#$ \\
\hline \multicolumn{5}{|l|}{ Wire hang test ( 2 trials $5 \mathrm{~s})$} \\
\hline Strength (mean latency to fall, s) & $3.5 \pm 0.2$ & $3.0 \pm 0.2$ & $4.6 \pm 0.0 * * *$ & $4.6 \pm 0.1 * * *$ \\
\hline Coordination (mean distance, $\mathrm{cm}$ ) & $0.5 \pm 0.1$ & $0.5 \pm 0.2$ & $1.2 \pm 0.1 * * *$ & $0.6 \pm 0.1^{\# \# \#}$ \\
\hline Elements of support $(n)$ & $1.2 \pm 0.1$ & $0.8 \pm 0.1^{\#}$ & $2.2 \pm 0.0^{* * * *}$ & $2.2 \pm 0.1 * * *$ \\
\hline \multicolumn{5}{|l|}{ Wire hang test ( 1 trial $60 \mathrm{~s})$} \\
\hline Strength (mean latency to fall, s) & $17.4 \pm 6.0$ & $19.2 \pm 8.9$ & $48.2 \pm 6.1 *$ & $48.4 \pm 7.7 *$ \\
\hline Coordination (mean distance, $\mathrm{cm}$ ) & $1.3 \pm 0.5$ & $0.9 \pm 0.5$ & $2.0 \pm 0.5$ & $1.9 \pm 0.5$ \\
\hline Elements of support $(n)$ & $1.6 \pm 0.4$ & $0.9 \pm 0.5$ & $2.8 \pm 0.3^{*}$ & $2.6 \pm 0.2 *$ \\
\hline
\end{tabular}

Note: NonTg SED and Tg SED, non transgenic and 3xTg-AD female mice housed in standard conditions; NonTg EXE 1 mo and Tg EXE-1 mo, non transgenic and 3xTg-AD female mice allowed free access to a running wheel during 1 month (week 1 to week 5 of the study) at 3 months of age. Results are the mean \pm SEM. Significant (Newman-Keuls post hoc test) differences between groups: ${ }^{*} p<0.05,{ }^{* *} p<0.01,{ }^{* * *} p<0.001$ compared to the corresponding NonTg mice; ${ }^{\#} p<0.05$, $\#$ \#\# $p<0.001$ compared to corresponding SED mice.

strength in females (Table 1D). At this age, both 1 month and 6 months of exercise exposure increased coordination in both genders of $3 \times \mathrm{Tg}$-AD mice (Tables 1C, D). In 7-month-old male mice, two-way ANOVA indicated an effect of factor 'genotype' in the rod tests and hang tests [all F's $(1,66)>6.13, p<0.0159$ ] and an effect of factor 'exercise' in the wooden rod test coordination and the wire rod test equilibrium and coordination tests [all F's ${ }_{(2,66)}>3.43, p<0.05$ ]. In the female mice, two-way ANOVA showed an effect of 'genotype' in coordination in the wooden rod test and hang tests, equilibrium in rod tests, strength in wire hang test $1 \times 60 \mathrm{~s}$ and elements of support in both hang tests [all F's $(1,63)>13.60, p<0.0005]$ and of 'exercise' in coordination in the wooden hire test $\left[\mathrm{F}_{(1,63)}=9.33\right.$, $p<0.0001]$.

\section{Exercise did not significantly ameliorate neophobia in the corner test}

Neophobia shown by 4-month-old 3xTg-AD mice (Tables 2 A, B) was not ameliorated by exercise. Two-way ANOVA showed significant effects of factor 'genotype' in the number of corners $\left[\mathrm{F}_{(1,36)}=10.80\right.$, $p=0.0023]$ and factor 'exercise' in the vertical activity $\left[\mathrm{F}_{(1,36)}=5.27, p=0.0276\right]$ in males, but did not reach factor significances in females. At 7 months of age, decreased exploration of a new cage by male $3 \mathrm{xTg}-\mathrm{AD}$ as compared to NonTg mice was neither ameliorated by exercise (Table 2C). However, female $3 \times \mathrm{Tg}$-AD mice showed similar responses to NonTg mice (Table 2D). At this age, two-way ANOVA showed an effect of factor 'genotype' in all measures in males and in vertical activity in females [all F's $>7.12$, $p<0.0096$ ] and of factor 'exercise' in the number of corners in males and in vertical activity in females [both F's $>3.47, p<0.0369$ ]. Exercise induced minor changes in NonTg mice.

\section{Exercise did not significantly modify open field test outcome}

The results of horizontal and vertical activity in the open field test are shown in Fig. 3A-D. The results of the other parameters tested are listed in Tables 2A-D. Female $3 \times T g-A D$ mice at 4 months of age and both genders at 7 months showed decreased horizontal activity (Fig. 3A, B). Four-month-old females also showed decreased vertical activity as compared to NonTg mice (Fig. 3D). Two-way ANOVA showed an effect of factor 'genotype' in the horizontal activity of all animal groups [all F's $>8.66, p<0.0045$ ] and in 


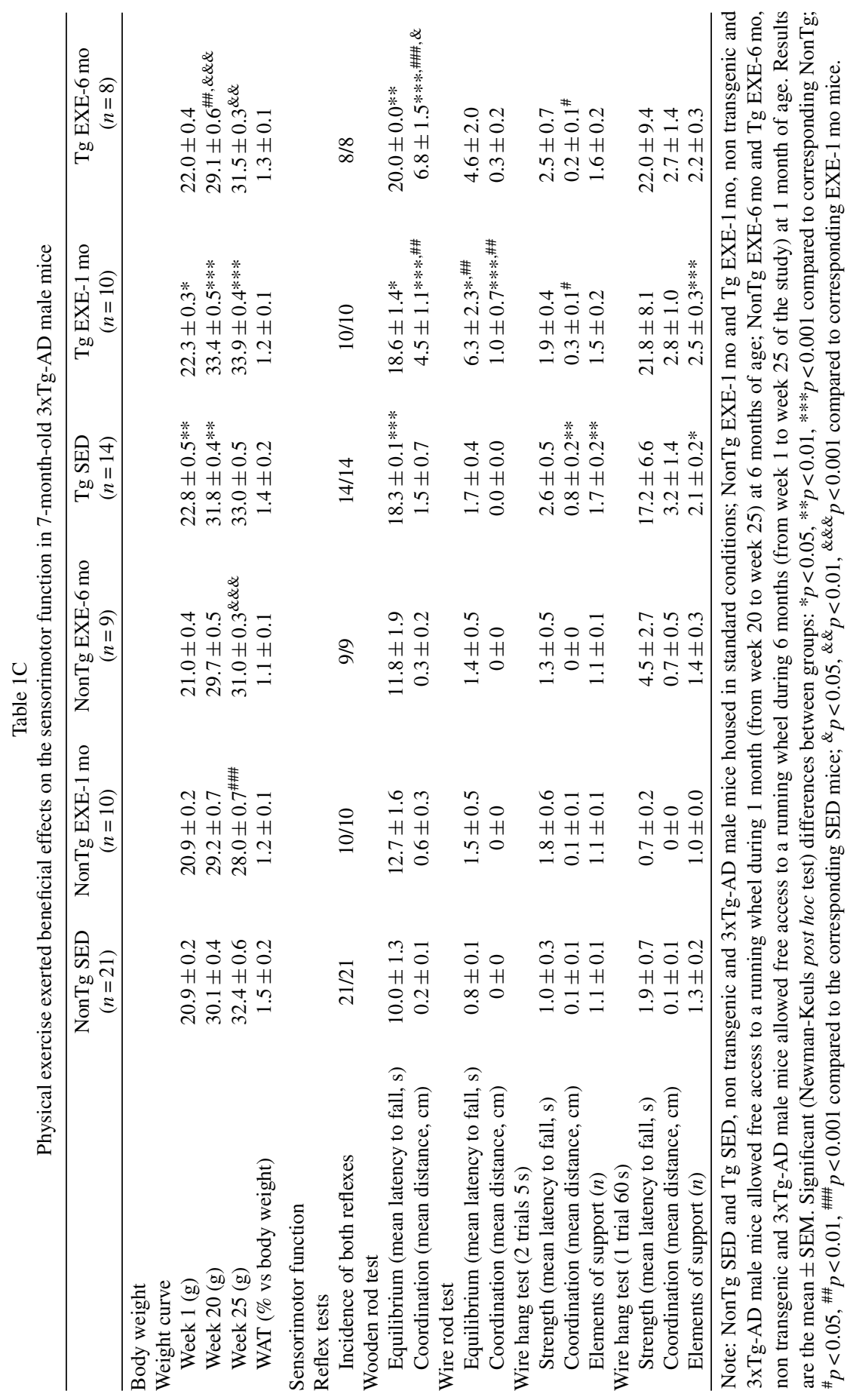




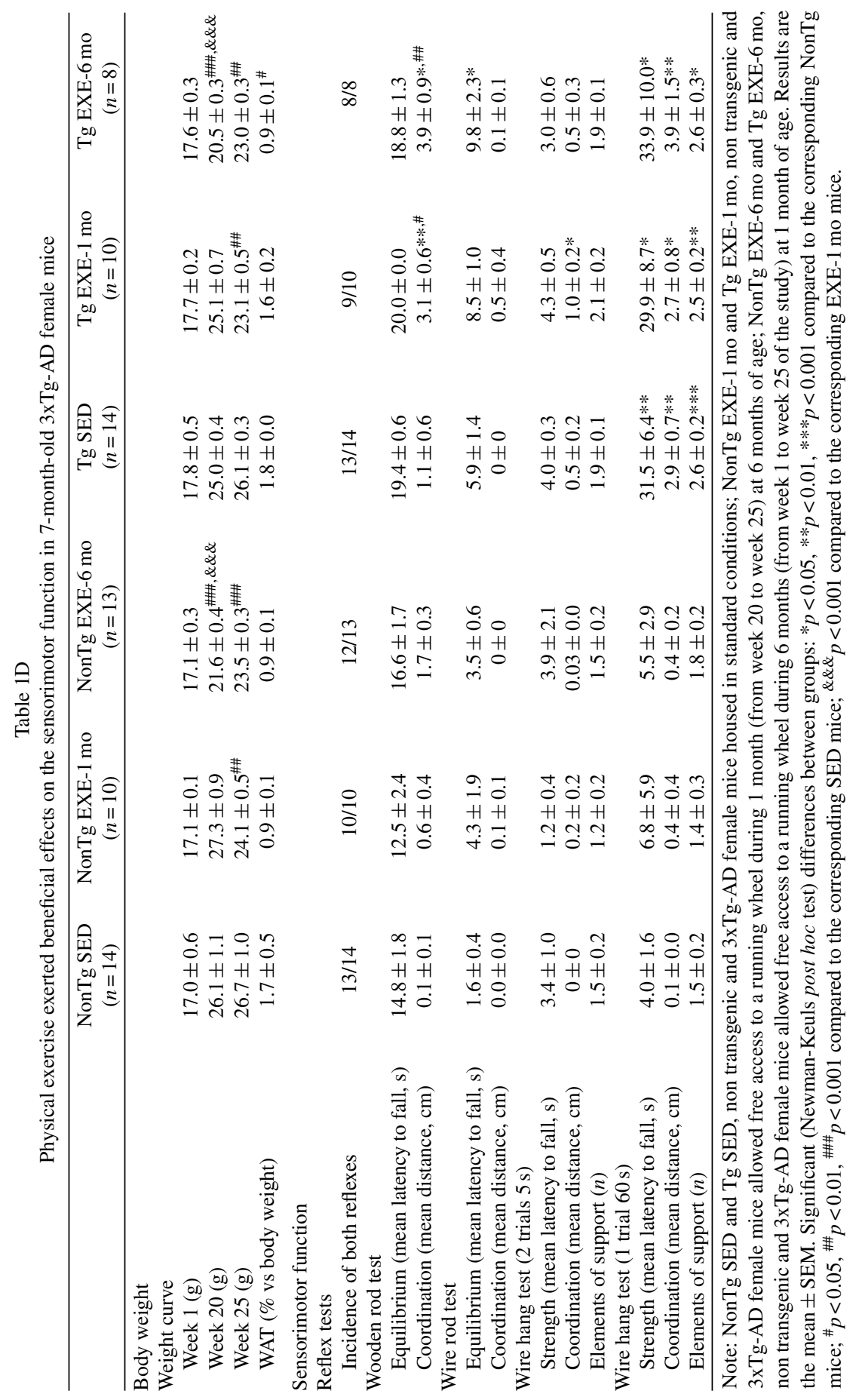


Table $2 \mathrm{~A}$

BPSD-like behaviors were barely present in 4-month-old 3xTg-AD male mice

\begin{tabular}{|c|c|c|c|c|}
\hline & $\begin{array}{l}\text { NonTg SED } \\
\quad(n=10)\end{array}$ & $\begin{array}{c}\text { NonTg EXE-1 mo } \\
(n=10)\end{array}$ & $\begin{array}{l}\text { Tg SED } \\
(n=10)\end{array}$ & $\begin{array}{c}\text { Tg EXE-1 mo } \\
(n=10)\end{array}$ \\
\hline \multicolumn{5}{|l|}{ Corner test } \\
\hline Vertical activity (latency, s) & $13.0 \pm 2.4$ & $20.0 \pm 2.9$ & $21.8 \pm 3.5$ & $22.0 \pm 2.5$ \\
\hline Number of corner $(n)$ & $5.9 \pm 0.6$ & $4.5 \pm 1.1$ & $3.0 \pm 0.6^{*}$ & $2.4 \pm 0.6$ \\
\hline Vertical activity $(n)$ & $3.5 \pm 0.8$ & $1.1 \pm 0.5^{\#}$ & $1.4 \pm 0.7 *$ & $1.0 \pm 0.3$ \\
\hline \multicolumn{5}{|l|}{ Open field test } \\
\hline Initial movement (latency, s) & $3.6 \pm 0.9$ & $2.5 \pm 0.2$ & $6.1 \pm 2.9$ & $3.1 \pm 0.9$ \\
\hline Exit of the center (latency, s) & $12.4 \pm 6.4$ & $6.2 \pm 0.7$ & $18.7 \pm 5.9$ & $19.7 \pm 4.7$ \\
\hline Entrance to periphery (latency, s) & $30.4 \pm 11.6$ & $15.7 \pm 4.0$ & $50.5 \pm 28.4$ & $59.4 \pm 21.3$ \\
\hline Vertical activity (latency, s) & $22.3 \pm 3.7$ & $60.7 \pm 23.5$ & $50.6 \pm 14.4$ & $56.4 \pm 21.3$ \\
\hline Self-grooming (latency, s) & $149.1 \pm 20.1$ & $156.8 \pm 21.4$ & $192.0 \pm 25.4$ & 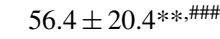 \\
\hline Horizontal activity $(\mathrm{cm})$ & See Fig. 3A & & & \\
\hline Vertical activity $(n)$ & See Fig. 3C & & & \\
\hline Total self-grooming duration (s) & $5.6 \pm 1.1$ & $8.0 \pm 2.5$ & $6.8 \pm 1.1$ & $6.8 \pm 1.5$ \\
\hline Defecation boli $(n)$ & $2.6 \pm 0.3$ & $2.5 \pm 0.5$ & $3.2 \pm 0.5$ & $3.0 \pm 0.4$ \\
\hline \multicolumn{5}{|l|}{ Dark and light box test } \\
\hline Latency to enter into the lit area (s) & See Fig. 3E & & & \\
\hline Time in lit area (s) & $105.6 \pm 23.1$ & $132.7 \pm 22.5$ & $146.0 \pm 22.1$ & $83.2 \pm 16.7$ \\
\hline Entrance to the lit area $(n)$ & $5.9 \pm 0.9$ & $4.6 \pm 0.7$ & $4.1 \pm 0.6$ & $4.6 \pm 0.8$ \\
\hline Defecation boli $(n)$ & $1.3 \pm 0.4$ & $1.6 \pm 0.6$ & $3.1 \pm 0.5$ & $1.5 \pm 0.6$ \\
\hline \multicolumn{5}{|l|}{ Boissier's 4 hole-board test } \\
\hline Initial movement (latency, s) & $1.2 \pm 0.5$ & $2.2 \pm 0.9$ & $13.1 \pm 6.2$ & $10.1 \pm 2.3$ \\
\hline Primer hole (latency, s) & $15.9 \pm 3.2$ & $52.6 \pm 28.5$ & $91.3 \pm 36.8$ & $45.0 \pm 19.2$ \\
\hline Four hole (latency, s) & $211 \pm 30.4$ & $182.8 \pm 30.8$ & $237.2 \pm 26.7$ & $235.8 \pm 29.2$ \\
\hline Time head-dipping (s) & See Fig. 3G & & & \\
\hline Number of head-dipping $(n)$ & $14.9 \pm 4.3$ & $16.4 \pm 3.1$ & $11.0 \pm 2.4$ & $18.4 \pm 2.7$ \\
\hline Defecation boli $(n)$ & $2.8 \pm 0.7$ & $2.7 \pm 0.5$ & $3.5 \pm 0.5$ & $3.1 \pm 0.5$ \\
\hline
\end{tabular}

Note: NonTg SED and Tg SED, non transgenic and 3xTg-AD male mice housed in standard conditions; NonTg EXE-1 mo and Tg EXE-1 mo, non transgenic and 3xTg-AD male mice allowed free access to a running wheel during 1 month at 3 months of age. Results are the mean \pm SEM. Significant (Newman-Keuls post hoc test) differences between groups: $* p<0.05$, $* * p<0.01$ compared to the corresponding NonTg mice; ${ }^{\#} p<0.05,{ }^{\# \#} p<0.001$ compared to the corresponding SED mice.

the vertical activity of 4-month-old mice [both genders $\left.\mathrm{F}_{(1,36)}>5.1, p<0.0297\right]$. Factor 'exercise' was significant in the horizontal activity of females at both ages and in the vertical activity of 4-month-old females [all F's $>3.19, p<0.0484$ ]. As regards to grooming and latency parameters (Tables 2A-D), 4-month-old females showed increased latency of grooming. Exercise treatment did not ameliorate these effects and did not significantly affect NonTg mouse behavior. However the increased latency of movement of 4month-old female $3 \times \mathrm{Tg}-\mathrm{AD}$ mice was reduced by exercise (Table 2B). ANOVA showed a significant effect of factor 'genotype' in latency of movement and self-grooming latency in 4-month-old female mice, latency of movement and latency and total selfgrooming in both genders of 7-month-old mice, latency of exit of the center in 7-month-old female mice, and latency of entrance to periphery in 7-month-old male mice [all F's $>4.14, p<0.0494$ ]. Significance of factor 'exercise' was observed in self-grooming latency in 4-month-old males, total self-grooming in 7-monthold females, and latency of movement in 4-month-old females and both genders of 7-month-old mice [all F's $>3.51, p<0.0357]$.

\section{Exercise reduced anxiety triggered in the dark-light box}

The results of latency to enter into lit area are shown in Fig. 3E, F. The results of the other parameters tested are listed in Tables 2A-D. No significant anxiety changes were detected at 4 months of age in 3xTg-AD mice (Tables 2A, B, Fig. 3E, F). However, 7-month-old 3xTg-AD mice of both genders showed a higher latency to enter the lit area than NonTg mice, while exercise ameliorated this response (Fig. 3E, F). Males also showed a lower number of entries (Table 2C). Six months of exercise was a more effective treatment period than 1 month in females (Fig. 3F). Two-way ANOVA showed an effect of factor 'genotype' in the latency to enter to the lit area in males and females at both ages tested [all F's $>4.09$, $p<0.0472$ ], whereas the effect of factor 'exercise' was significant in the time in lit area in 7-month-old females $\left[\mathrm{F}_{(2,58)}=4.48, p=0.0155\right]$ and number of entrances to 
Table 2B

Some BPSD-like behaviors were shown by 4-month-old 3xTg-AD female mice

\begin{tabular}{|c|c|c|c|c|}
\hline & $\begin{array}{l}\text { NonTg SED } \\
\quad(n=10)\end{array}$ & $\begin{array}{c}\text { NonTg EXE-1 mo } \\
\quad(n=10)\end{array}$ & $\begin{array}{l}\text { Tg SED } \\
(n=10)\end{array}$ & $\begin{array}{c}\text { Tg EXE-1 mo } \\
(n=10)\end{array}$ \\
\hline \multicolumn{5}{|l|}{ Corner test } \\
\hline Vertical activity (latency, s) & $13.6 \pm 2.2$ & $14.4 \pm 3.0$ & $21.0 \pm 2.0$ & $16.6 \pm 2.3$ \\
\hline Number of corner $(n)$ & $6.7 \pm 1.0$ & $5.2 \pm 0.9$ & $4.7 \pm 0.7$ & $4.4 \pm 0.7$ \\
\hline Vertical activity $(n)$ & $3.6 \pm 0.9$ & $1.5 \pm 0.3^{\#}$ & $1.3 \pm 0.3 *$ & $2.0 \pm 0.6$ \\
\hline \multicolumn{5}{|l|}{ Open field test } \\
\hline Initial movement (latency, s) & $5.9 \pm 1.4$ & $3.1 \pm 0.8$ & $13.1 \pm 3.6^{*}$ & $6.3 \pm 1.4^{\#}$ \\
\hline Exit of the center (latency, s) & $9.7 \pm 1.6$ & $26.2 \pm 15.2$ & $19.0 \pm 4.5$ & $14.0 \pm 3.8$ \\
\hline Entrance to periphery (latency, s) & $17.7 \pm 4.4$ & $30.5 \pm 15.4$ & $30.6 \pm 6.4$ & $21.6 \pm 6.2$ \\
\hline Vertical activity (latency, s) & $47.8 \pm 15.2$ & $72.7 \pm 25.9$ & $42.4 \pm 12.4$ & $64.6 \pm 25.4$ \\
\hline Self-grooming (latency, s) & $143.2 \pm 15.2$ & $142.2 \pm 24.5$ & $166.4 \pm 26.1$ & $209.1 \pm 21.1$ \\
\hline Horizontal activity $(\mathrm{cm})$ & See Fig. 3B & & & \\
\hline Vertical activity $(n)$ & See Fig. 3D & & & \\
\hline Total self-grooming duration (s) & $5.2 \pm 1.5$ & $7.5 \pm 1.8$ & $6.2 \pm 1.7$ & $5.3 \pm 1.2$ \\
\hline Defecation boli $(n)$ & $2.1 \pm 0.4$ & $2.4 \pm 0.3$ & $3.2 \pm 0.7$ & $2.3 \pm 0.3$ \\
\hline \multicolumn{5}{|l|}{ Dark and light box test } \\
\hline Latency to enter into the lit area (s) & See Fig. 3F & & & \\
\hline Time in lit area (s) & $109.1 \pm 12.6$ & $89.2 \pm 12.5$ & $121.7 \pm 26.7$ & $91.2 \pm 16.8$ \\
\hline Entrance to the lit area $(n)$ & $6.8 \pm 0.7$ & $4.9 \pm 0.6$ & $5.7 \pm 0.5$ & $6.7 \pm 0.8$ \\
\hline Defecation boli $(n)$ & $1.0 \pm 0.4$ & $1.3 \pm 0.4$ & $1.0 \pm 0.3$ & $1.2 \pm 0.4$ \\
\hline \multicolumn{5}{|l|}{ Boissier's 4 hole-board test } \\
\hline Initial movement (latency, s) & $1.4 \pm 0.7$ & $1.3 \pm 0.5$ & $9.5 \pm 5.6$ & $24.7 \pm 7.11^{* *, \#}$ \\
\hline Primer hole (latency, s) & $20.6 \pm 3.9$ & $11.2 \pm 2.6$ & $63.5 \pm 22.6$ & $80.8 \pm 26.3 *$ \\
\hline Four hole (latency, s) & $175.7 \pm 27.2$ & $216.7 \pm 30.6$ & $249.0 \pm 25.3$ & $237.0 \pm 27.1$ \\
\hline Time head-dipping (s) & See Fig. $3 \mathrm{H}$ & & & \\
\hline Number of head-dipping $(n)$ & $15.9 \pm 3.3$ & $22.0 \pm 2.3$ & $9.9 \pm 2.1$ & $12.8 \pm 2.4$ \\
\hline Defecation boli $(n)$ & $3.3 \pm 0.7$ & $2.3 \pm 0.5$ & $2.8 \pm 0.6$ & $1.8 \pm 0.5$ \\
\hline
\end{tabular}

Note: NonTg SED and Tg SED, non transgenic and 3xTg-AD female mice housed in standard conditions; NonTg EXE-1 mo and Tg EXE-1 mo, non transgenic and 3xTg-AD female mice allowed free access to a running wheel during 1 month at 3 months of age. Results are the mean \pm SEM. Significant (Newman-Keuls post hoc test) differences between groups: $* p<0.05$, $* * p<0.01$ compared to the corresponding NonTg mice; ${ }^{\#} p<0.05$ compared to the corresponding SED mice.

the lit area in 7-month-old male mice $\left[\mathrm{F}_{(2,66)}=8.07\right.$, $p=0.0007]$.

\section{Exercise improved exploratory behavior in the hole-board}

The results of total dipping time are shown in Fig. 3G, H. The results of the other parameters tested are listed in Tables 2A-D. No significant changes were detected in the hole-board test in the 4-monthold 3xTg-AD mice (Tables 2A, B, Fig. 3G, H). At 7 months of age, male and female NonTg mice showed higher total dipping activity than the younger NonTg mice (Fig. 3G, H). At 7 months, the amount of time spent dipping by $3 \times \mathrm{Tg}$-AD mice was less than that of NonTg mice and exercise increased it to NonTg levels (Fig. 3G, H). The decreased latency to explore the first hole was also ameliorated by exercise (Table 2C). The 6-month exercise treatment was more effective than the shorter 1-month treatment. Two-way ANOVA showed an effect of factor 'genotype' in the latency of movement in 4-month-old males and females and 7 month-old males [all F's $>8.78, \mathrm{p}<0.0054$ ], latency to primer hole in 4-month-old females $\left[\mathrm{F}_{(1,36)}=10.33\right.$, $p<0.0028$ ], number of head-dipping in 4-monthold females and 7-month-old males [both F's $>7.81$, $p<0.0083$ ] and dipping time in 7-month-old male mice $\left[\mathrm{F}_{(1,64)}=8.49, p<0.0049\right]$. The effect of factor 'exercise' was significant in the latency to primer hole, number of head-dipping and defecation boli in 4-month-old females [all F's $=4.44, p<0.0154$ ] and in the total dipping time in 7-month-old male mice $\left[\mathrm{F}_{(2,64)}=15.05, p<0.0001\right]$.

\section{Exercise ameliorated the retention deficiency in the Morris water maze}

Latencies of escape in the place task acquisition, either in 4-month-old (Fig. 4A, B) or 7-month-old mice (Fig. 4E, F), were similar between the different groups of males. However, female acquisition curves showed a significant difference by group. Two-way ANOVA showed an effect of factor 'group' at both 4 months $\left[\mathrm{F}_{(3,216)}=3.646, p=0.0260\right]$ and 7 months of age $\left[\mathrm{F}_{(5,348)}=19.90, p<0.0001\right]$ in female mice. The factor 'day' was significant in males and females 


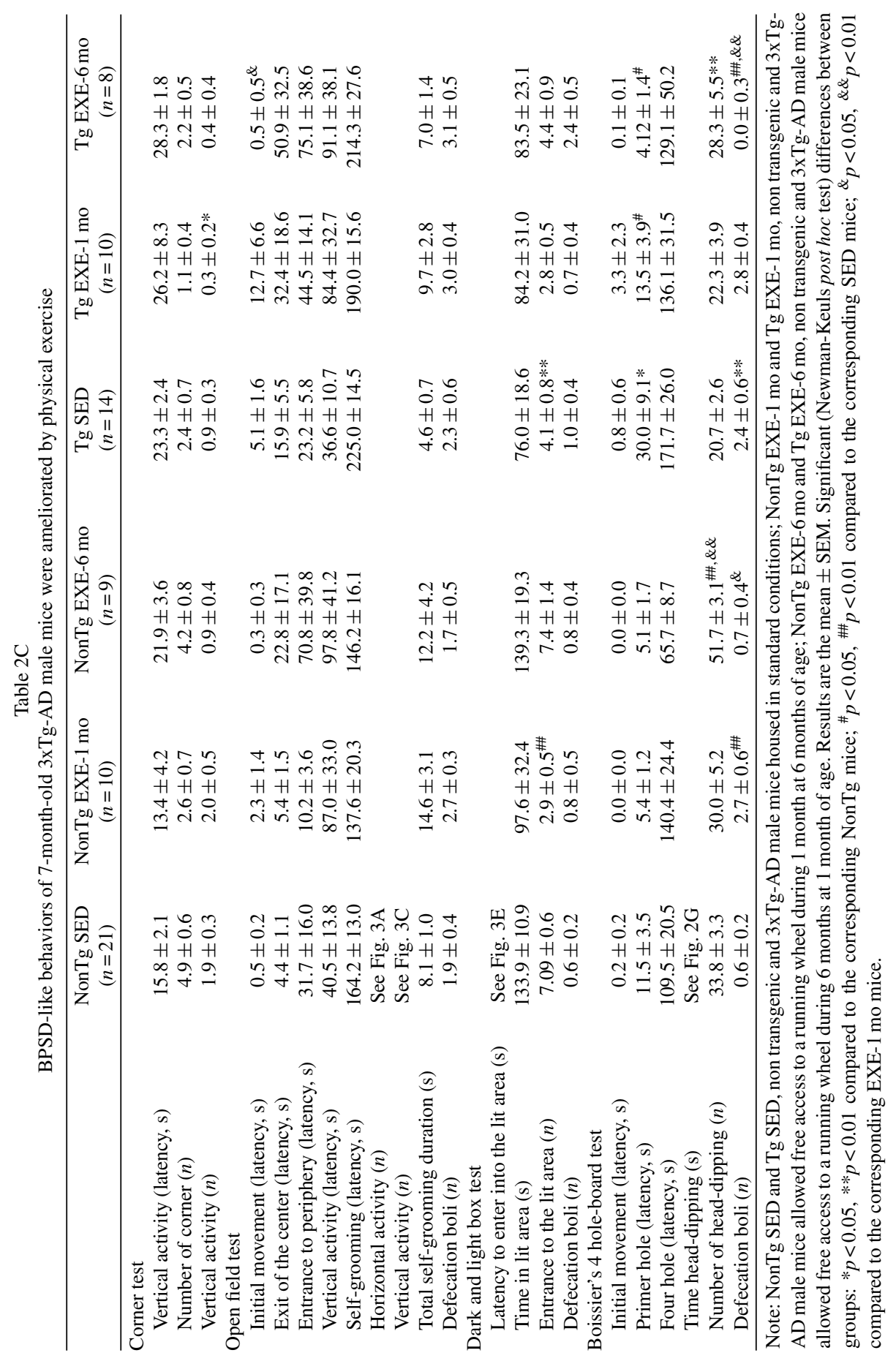




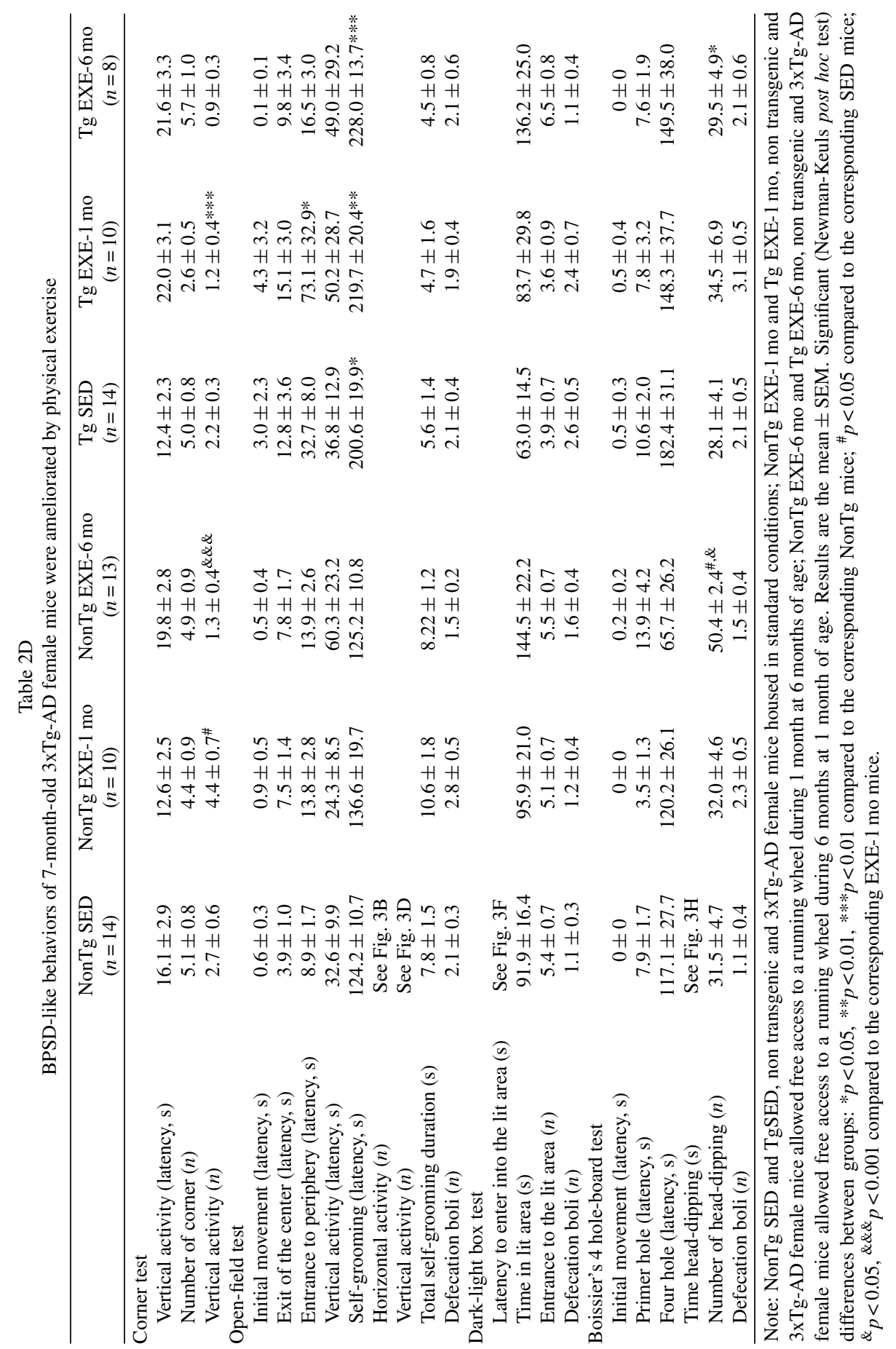


OPEN FIELD TEST

Total horizontal activity

A

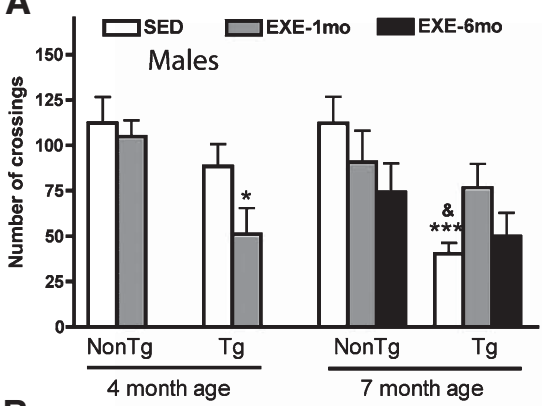

B

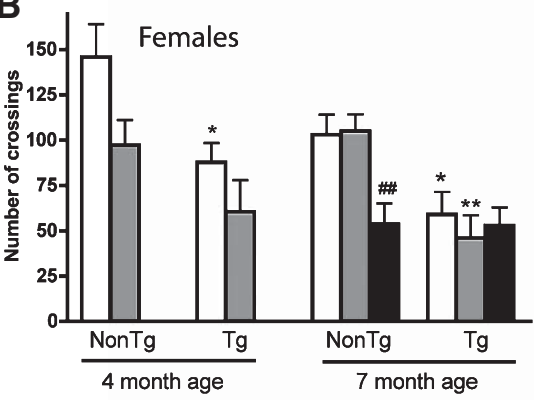

C

Total vertical activity

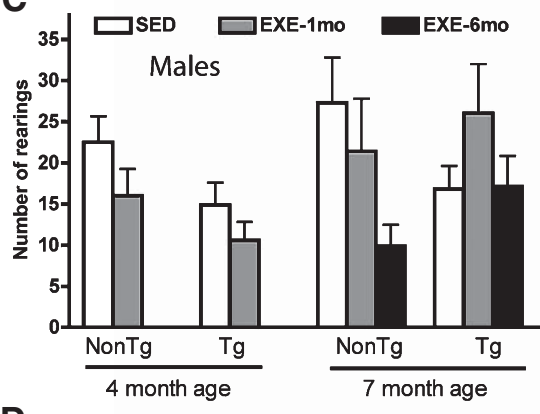

D

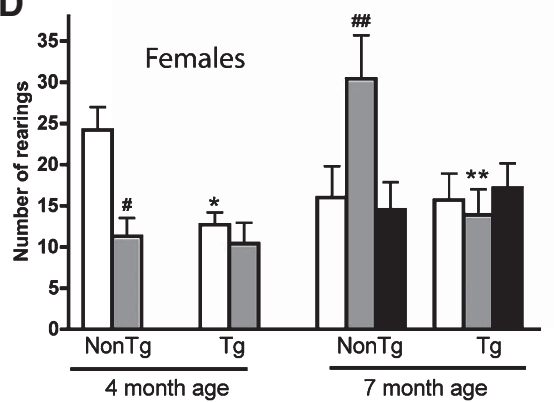

DARK \& LIGHT BOX TEST
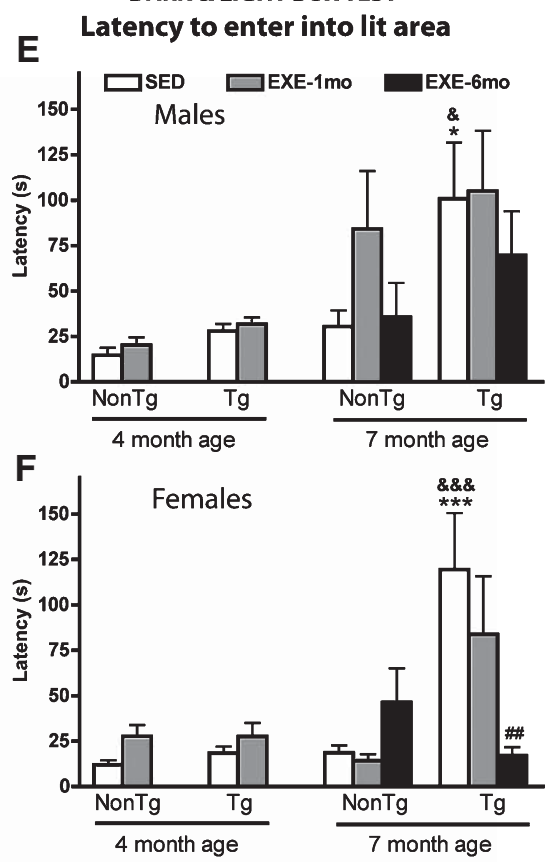

BOISSIER'S HOLE BOARD TEST Total dipping time

G

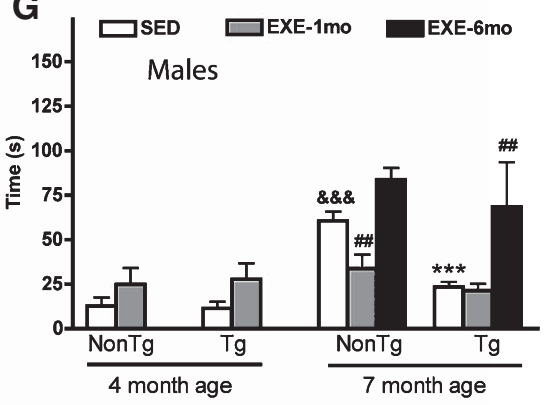

H

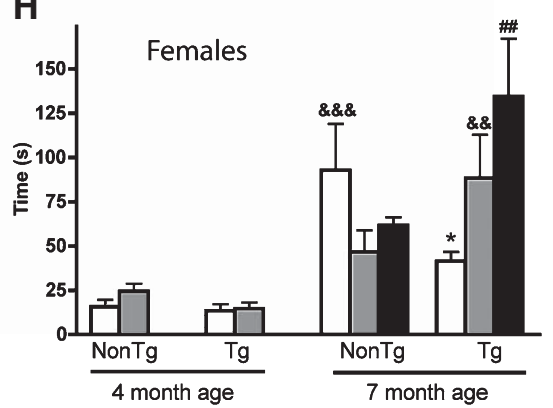

Fig. 3. Physical exercise partially ameliorated the behavioral and psychological symptoms of dementia (BPSD)-like in 3xTg-AD mice. The behavioral tests showed the presence of BPSD-like symptoms in 3xTg-AD mice mainly in 4-month-old females and in both genders of 7-monthold 3xTg-AD mice. A) and B) Decreased activity in the open field activity was not ameliorated by exercise. E) and F) Anxiety in the dark and light box test was totally reduced to NonTg levels by 6 months of exercise, with a better response in females. G) and H) Exploratory activity was increased to NonTg levels after 6 months of exercise in both genders. For experimental groups see legend to Fig. 1, and for complementary data see Tables 1A, B. Values are the mean \pm SEM. Statistics: Two-way ANOVA followed by Bonferroni's post hoc test. Significant differences between groups: ${ }^{*} p<0.05,{ }^{* *} p<0.01,{ }^{*} * *<<0.001$, Tg mice compared to the corresponding treatment group of NonTg mice, ${ }^{\# \#} p<0.01$, EXE mice compared to the corresponding genotype group of SED mice; ${ }^{\&} p<0.05,{ }^{\&} \&<0.01$, \&\&\& $p<0.001,7$ month-old mice compared to the corresponding group of 4-month-old mice. 
A

\section{Place task: 4 month age}

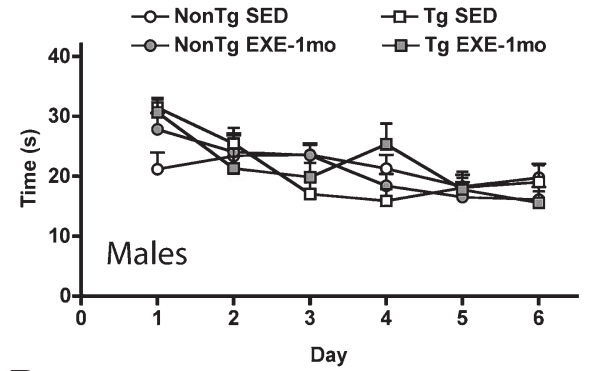

B

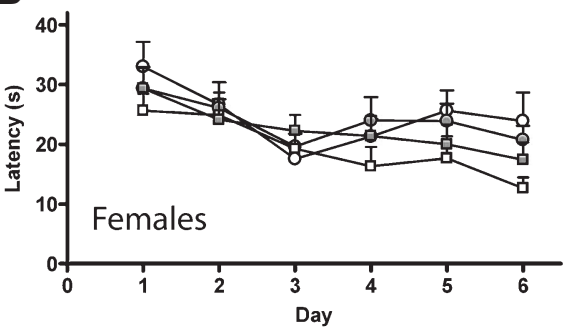

Removal: 4 month age

C

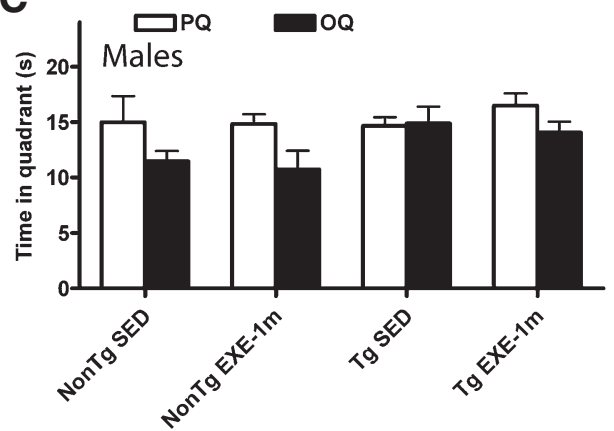

D

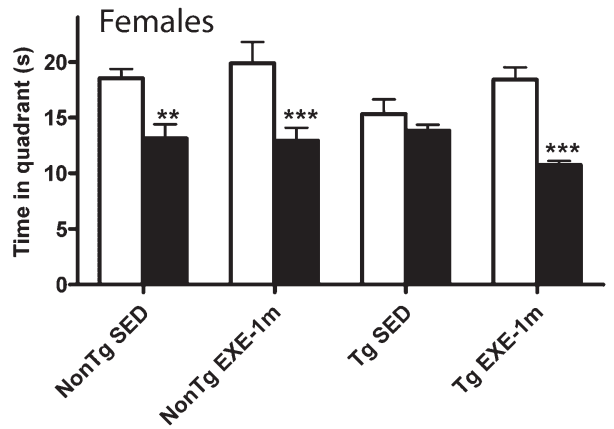

E

Place task: 7 month age

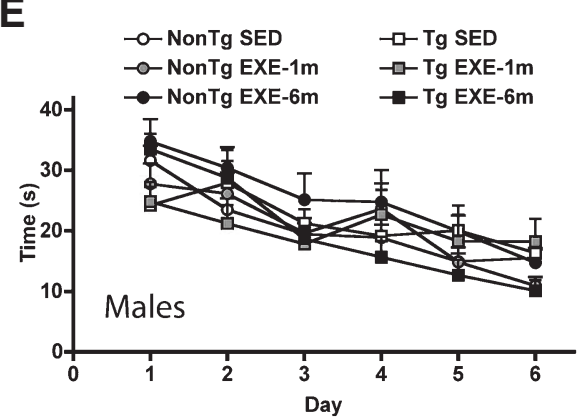

F

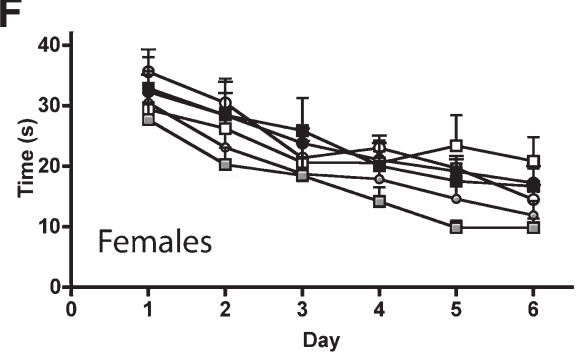

Removal: 7 month age

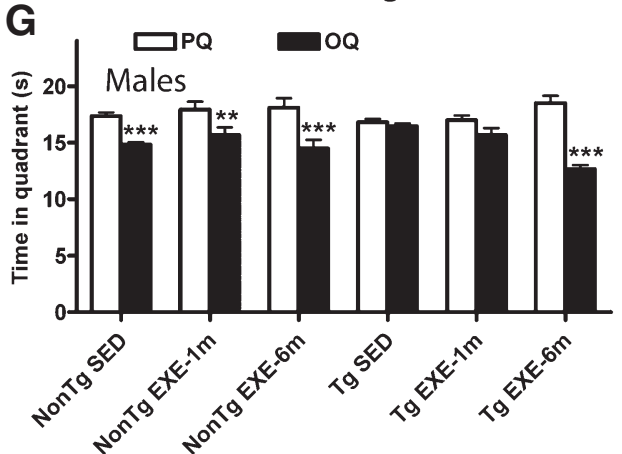

H

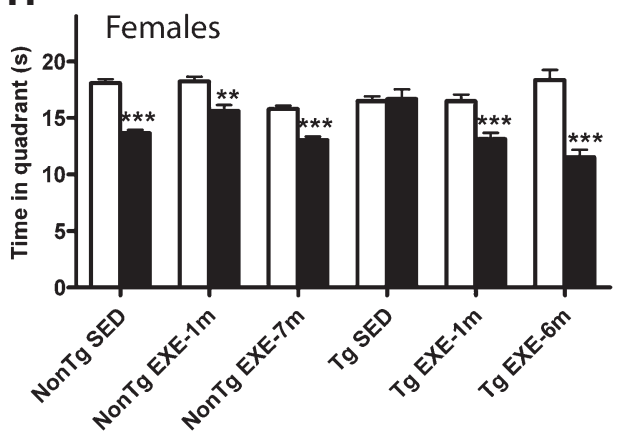

Fig. 4. Physical exercise protected 3xTg-AD mice from spatial memory deterioration as shown by the retention of learning in the Morris water maze (MWM). Both 4-month-old (A-D) and 7-month-old 3xTg-AD mice (E-H) demonstrated an improved outcome after exercise that was more evident after 6 months of treatment in both genders. A, B, E, and F show the latencies of platform escape during acquisition of the place task; C, D, G, and $\mathrm{H}$ show the time spent swimming in the platform quadrant of the pool (PQ) and the opposite quadrant (OQ) in the probe trial in which the platform was removed to test the retention of learning. For experimental groups see legend to Fig. 1. Values are the mean \pm SEM. Statistics: Two-way ANOVA followed by Bonferroni's post hoc test. Significant differences between groups: $* * p<0.01, * * * p<0.001$ compared to the platform quadrant. 
[all F's $>6.27, p<0.0001$ ]. For both genders, a few scattered time points showed differences between exercise treatments (not shown). In the sedentary animal groups, the factor 'genotype' was significant in 4month-old females $\left[\mathrm{F}_{(1,108)}=7.18, p=0.0085\right]$. The factor 'exercise' was significant in 7-month-old male and female NonTg and female 3xTg-AD mice [all F's $>4.407, p<0.0134]$.

Retention of learning, as measured in the probe trial test, was absent in 3xTg-AD mice housed in sedentary conditions, both in 4-month-olds (Fig. 4C, D) and 7month-olds (Fig. 4G, H). The figures show a higher time spent in the quadrant from which the platform had been removed rather than in the opposed quadrant (the time spent in the right and left quadrants had been excluded from the histograms for reasons of clarity). All NonTg mice groups showed significant retention, but the dispersion of the data for 4-month-old males was too high for statistical differences [ANOVA, factor 'platform': all F's $>8.837, p<0.0040]$. Exercise did not change the responses of NonTg mice but improved the responses of $3 \mathrm{xTg}-\mathrm{AD}$ mice to NonTg levels. At 7 months of age, the 6-month training period was more effective than the 1-month training period. The best response of $3 \times \mathrm{Tg}-\mathrm{AD}$ mice to exercise was that of 7-month-old females [ANOVA, factor 'exercise': $\left.\mathrm{F}_{(2,58)}=3.918, p<0.0254\right]$.

\section{Exercise slightly ameliorated funcional deficits in startle response and prepulse inhibition}

The startle response in the three groups of 7-monthold animals was similar in latency $(12.1 \pm 1.1 \mathrm{~ms}$ for NonTg, $11.6 \pm 0.2 \mathrm{~ms}$ for $3 \mathrm{xTg}-\mathrm{AD}$, and $11.9 \pm 0.3 \mathrm{~ms}$ for $3 \mathrm{xTg}-\mathrm{AD}$ EXE mice). However, as shown in Fig. 5A, 3xTg-AD animals presented significant differences in the maximum peak latency $(28.2 \pm 1 \mathrm{~ms})$ with respect to the NonTg $(41.2 \pm 1.1 \mathrm{~ms})$ and $3 \times \mathrm{Tg}-\mathrm{AD}$ $\operatorname{EXE}(37.8 \pm 1.7 \mathrm{~ms})$ groups $\left[\mathrm{F}_{(2,32)}=27.7, p<0.001\right]$. Moreover, $3 \mathrm{xTg}-\mathrm{AD}$ and $3 \mathrm{xTg}$-AD EXE animals presented significant differences $\left[\mathrm{F}_{(2,32)}=42.1, p<0.001\right]$ compared to the NonTg ones, in terms of maximum peak value $(7.6 \pm 1.7 \mathrm{mN}$ for NonTgl, $59.7 \pm 5.1 \mathrm{mN}$ for $3 \mathrm{xTg}-\mathrm{AD}$, and $52.3 \pm 5.2 \mathrm{mN}$ for $3 \times \mathrm{Tg}-\mathrm{AD}$ EXE) and total area $(10.3 \pm 1.4 \mathrm{mN} \times \mathrm{s}$ for NonTg, $58.9 \pm 4.6 \mathrm{mN} \times \mathrm{s}$ for $3 \times \mathrm{Tg}-\mathrm{AD}$, and $69.1 \pm 7.6 \mathrm{mN} \times \mathrm{s}$ for $3 \mathrm{xTg}-\mathrm{AD} \mathrm{EXE})\left[\mathrm{F}_{(2,32)}=38.2\right.$, $p<0.001]$.

Similar differences were obtained in the indices of prepulse inhibition. Thus, the index related to response latency did not differ significantly between the three groups $(10.6 \pm 1.8$ for NonTg, $7.8 \pm 0.3$ for
A
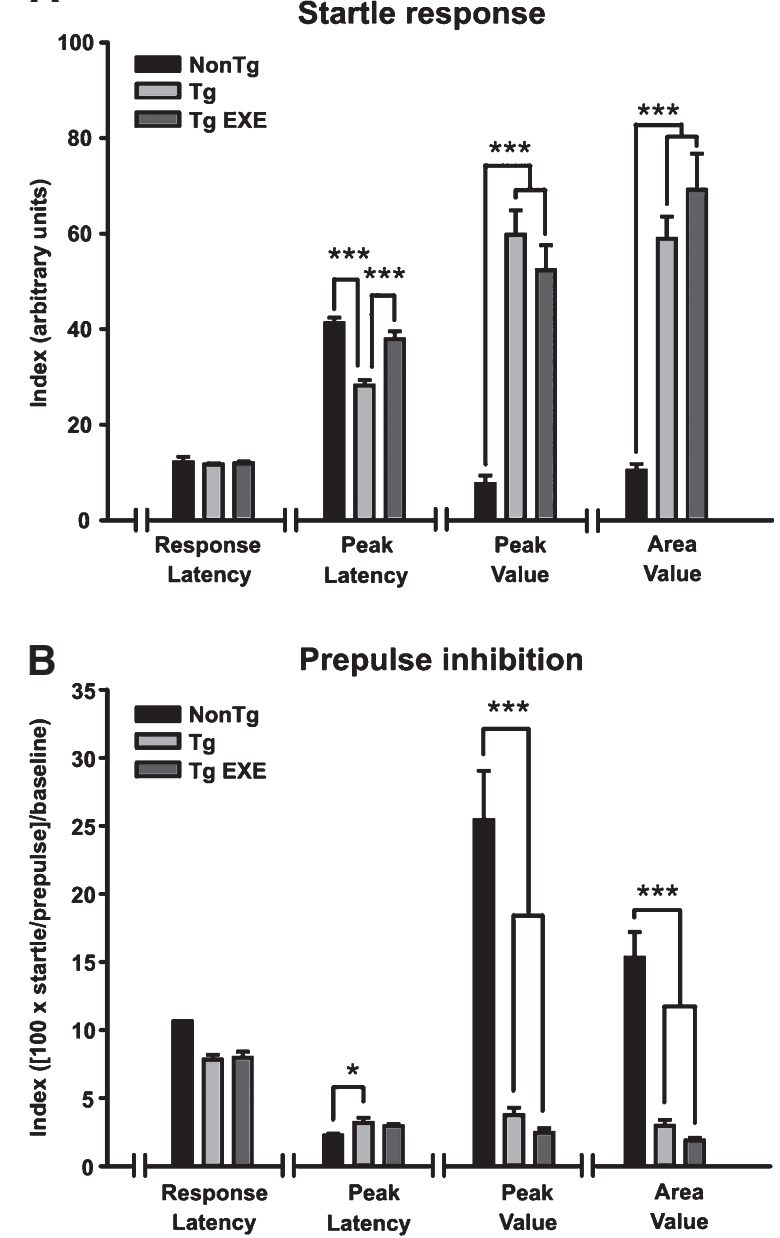

Fig. 5. Dysfunction of startle response and prepulse inhibition tasks in 3xTg-AD mice. A) Graphical representation of the values corresponding to response latency, maximum peak latency, maximum peak value, and total area collected from 7-month-old NonTg, 3xTg-AD, and 3xTg-AD EXE animals in the startle response task. B) Graphical representation of the indices ([(startle/prepulse ratio) $\times 100$ ]/baseline value) related to response latency, maximum peak latency, maximum peak value, and total area value obtained for the same groups of animals. Six months of exercise treatment in the 3xTg-AD EXE animals had a weak beneficial effect by normalizing the $3 x T g-A D$ maximun peak latency values to NonTg values. Data represents the mean \pm SEM of the obtained data. Statistics: Oneway ANOVA followed by Bonferroni's post hoc test. Significant differences between groups: $* p<0.05, * * * p<0.001$.

3xTg-AD, and $11.9 \pm 0.3$ for 3xTg-AD EXE mice). As shown in Fig. 5B, NonTg animals (performance index $=2.2 \pm 0.1$ ) presented significant differences $\left[\mathrm{F}_{(2,32)}=3.5, p<0.05\right]$ with respect to $3 \mathrm{xTg}-\mathrm{AD}$ mice (index $=3.1 \pm 0.3$ ), but not with respect to $3 \times \mathrm{Tg}-\mathrm{AD}$ EXE mice (index $=2.9 \pm 0.1$ ). Moreover, $3 \times T$ T-AD and 3xTg-AD EXE animals showed significant differences $\left[\mathrm{F}_{(2,32)}=36.6, p<0.001\right]$ compared to NonTg 
mice, in the indices related to maximum peak value $(25.4 \pm 3.6$ for NonTg, $3.7 \pm 0.5$ for $3 \times \mathrm{xT}-\mathrm{AD}$, and $2.4 \pm 0.3$ for $3 \times \mathrm{Tg}-\mathrm{AD}$ EXE) and total area $(15.3 \pm 1.8$ for NonTg, $2.9 \pm 0.4$ for $3 \times \mathrm{Tg}-\mathrm{AD}$, and $1.8 \pm 0.2$ for $3 \times \mathrm{Tg}-\mathrm{AD}$ EXE) $\left[\mathrm{F}_{(2,32)}=43.3, p<0.001\right]$.

Thus, 3xTg-AD mice presented some functional deficits in the elaboration of prepulse inhibition, correlated with a high level of startle response, when compared with the performance of NonTg animals. These deficits were less acute in $3 \times \mathrm{Tg}-\mathrm{AD}$ EXE animals.

\section{Exercise improved instrumental conditioning behavior}

Figure 6 illustrates the mean percentage of the maximum number of lever presses. The selected target was to obtain $\geq 20$ pellets in each one of the five sessions of the conditioning task. As shown, NonTg animals achieved $62 \pm 7.7 \%$ of this target in the $1 \mathrm{st}$ session, whilst $3 \times \mathrm{Tg}-\mathrm{AD}$ and $3 \times \mathrm{Tg}-\mathrm{AD}$ EXE mice achieved only $10.5 \pm 3.1 \%$ and $8.7 \pm 3.6 \%$, respectively. This was a significant difference $\left[\mathrm{F}_{(2,33)}=20.3\right.$, $p<0.001]$ as was that for the $2 \mathrm{nd} \operatorname{session}\left[\mathrm{F}_{(2,33)}=22.3\right.$, $p<0.001]$. During the last (5th) session, NonTg animals achieved $95 \pm 4.4 \%$ of the target, and 3xTg-AD and $3 \times$ Tg-AD EXE mice achieved $71.1 \pm 14.9 \%$ and $100 \%$, respectively. There were no significant differ-

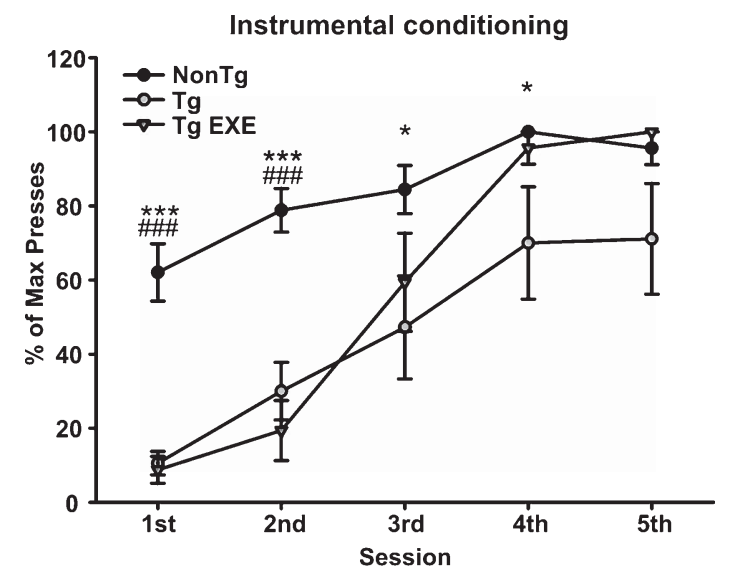

Fig. 6. Physical exercise ameliorated the instrumental conditioning reponse of 3xTg-AD mice in the Skinner box. Graphical representation of the percentage $(\%)$ of the maximum number of presses on the lever (the selected criterion was a total of 20 presses) carried out by NonTg, 3xTg-AD, and 3xTg-AD EXE animals during the five sessions of the task. Data are mean \pm SEM of the obtained percentages. Statistics: One-way ANOVA followed by Bonferroni's post hoc test. Symbols indicate significant differences between 3xTg-AD (*) and 3xTg-AD EXE (\#) versus NonTg animals. One symbol: $p<0.05$; three symbols: $p<0.001$. ences between the three groups during the 5 th training session $\left[\mathrm{F}_{(2,32)}=3.1, p=0.059\right]$. Interestingly, during the 3 rd and 4 th conditioning sessions, NonTg animals only differred significantly from the $3 \mathrm{xTg}-\mathrm{AD}$ animals $\left[\mathrm{F}_{(2,33)}=3.9, p<0.05\right.$ and $\mathrm{F}_{(2,33)}=4.8, p<0.05$, respectively], indicating the better performance of the 3xTg-AD EXE animals.

Physical exercise ameliorated the synaptic function and plasticity of $3 x T g-A D$ mice

\section{Exercise partially restored the input/output relationships at the CA1-medial prefrontal synapse to control values}

To check the functional state of the CA1-medial prefrontal synapse, we studied the changes in the amplitude of field EPSPs evoked at the medial prefrontal cortex by paired-pulse stimulation of the CA1 area, for a wide range of inter-stimulus intervals (10, $20,40,100,200$, and $500 \mathrm{~ms}$ ), and at increasing intensities (0.3-4.8 mA) in 7-month-old mice (Fig. 7). The CA1-medial prefrontal synapse presented a definite pattern of field EPSP facilitation and depression in response to paired-pulse stimulation in NonTg animals (Fig. 7A-C) depending on the selected intensity and inter-stimulus interval. As a whole, 3xTg-AD animals (Fig. 7D-F) produced higher values than their controls in this tridimensional representation of input/output curves, indicating the overactivation of the CA1-medial prefrontal synapse. However, the field EPSP 2/field EPSP 1 ratio did not show an enhanced facilitation effect but only some depression at the lowest inter-stimulus interval. Finally, 3xTgAD EXE animals, which had undergone 6 months of voluntary physical exercise, showed a pattern of facilitation/depression ranging between the NonTg and $3 \times$ Tg-AD groups (Fig. 7G-I). The comparison of pairs of fEPSPs evoked with equal intensity and interstimulus interval, yielded significant differences of the fEPSPs 2 amplitudes between groups at the $0.3 \mathrm{~mA}$ and $500 \mathrm{~ms}$ inter-stimulus interval point $\left[\mathrm{F}_{(2,13)}=4.69\right.$, $p<0.05]$, the $2.4 \mathrm{~mA}$ and $100 \mathrm{~ms}$ inter-stimulus point $\left[\mathrm{F}_{(2,13)}=5.33, p<0.05\right]$, and the $4.8 \mathrm{~mA}$ and $100 \mathrm{~ms}$ inter-stimulus interval point $\left[\mathrm{F}_{(2,13)}=6.39, p<0.05\right]$. Significant differences between the fEPSP2/fEPSP1 ratios were found at the $2.4 \mathrm{~mA}$ and $20 \mathrm{~ms}$ interstimulus interval point $\left[\mathrm{F}_{(2,13)}=4.69, p<0.05\right]$ and at the $2.4 \mathrm{~mA}$ and $500 \mathrm{~ms}$ inter-stimulus interval point $\left[\mathrm{F}_{(2,13)}=5.72, p<0.05\right]$ (Fig. 7). These results suggest that, in relation to neurotransmitter release at the CA1medial prefrontal cortex synapse, the effect of action potentials arriving at CA1 axon terminals in $3 \mathrm{xTg}$ - 
fEPSP 1
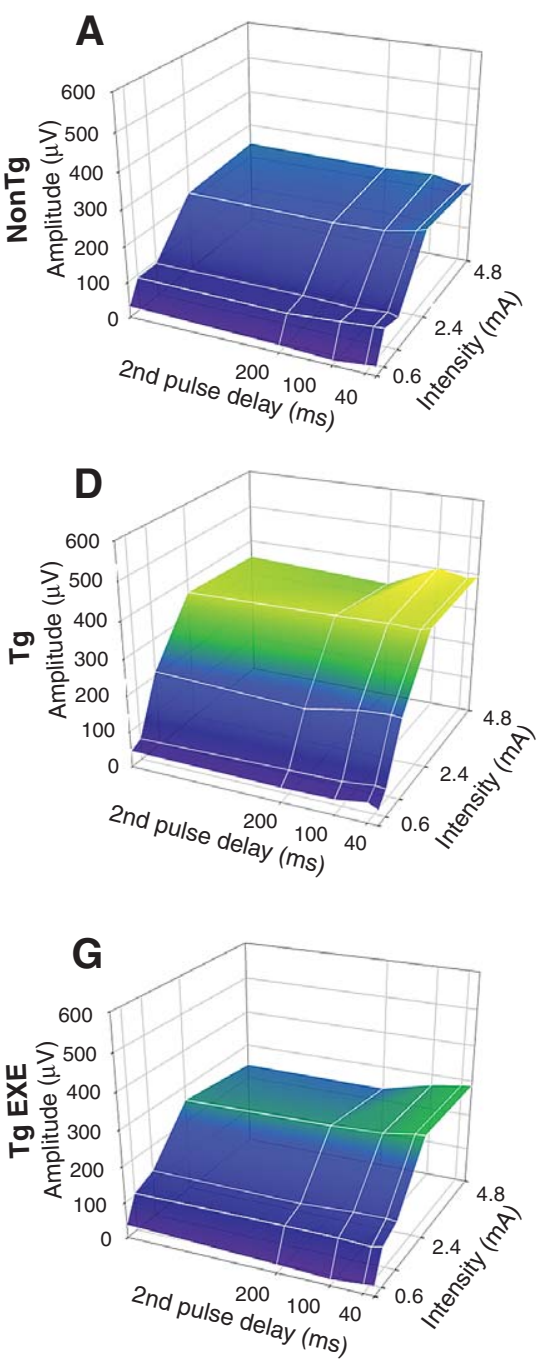

fEPSP 2
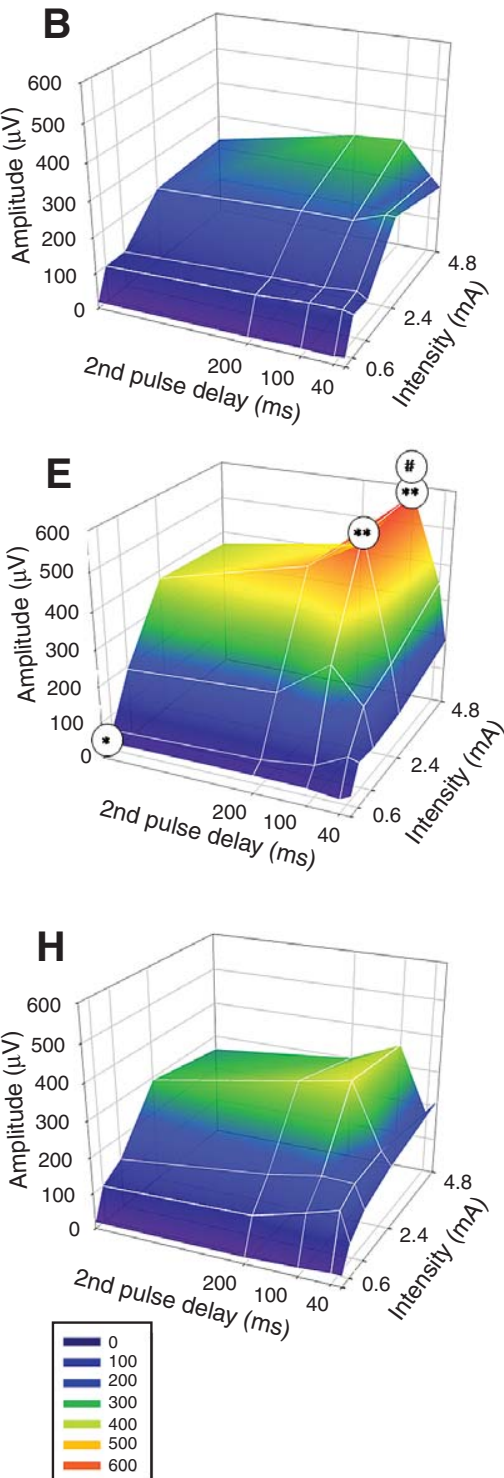

fEPSP 2 / fEPSP 1
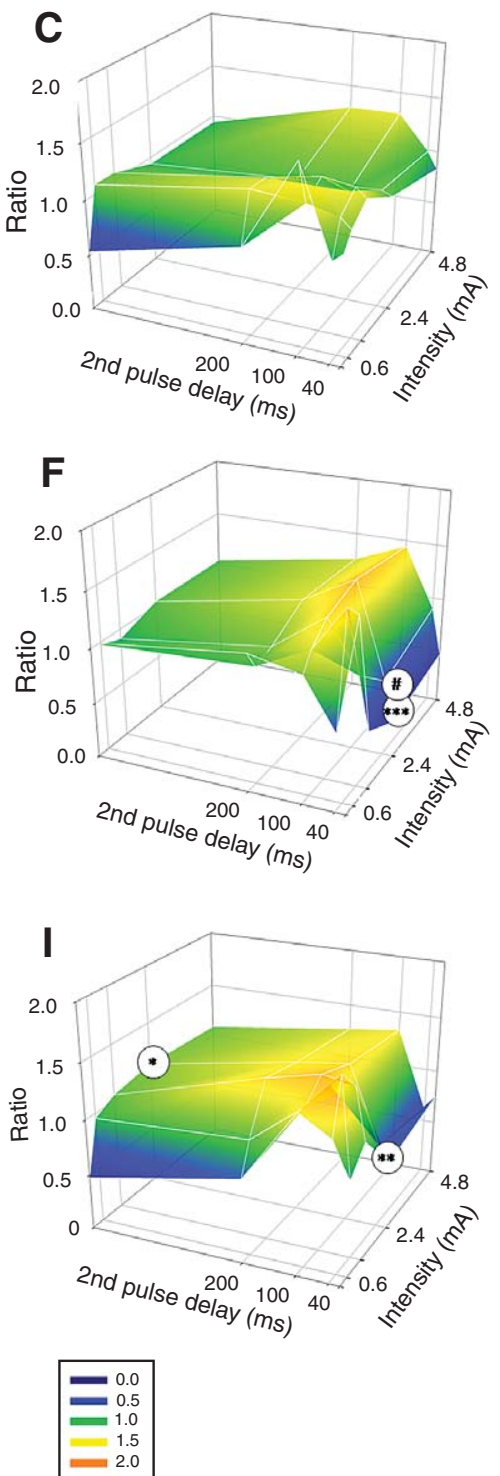

Fig. 7. Alterations in synaptic response to paired-pulse stimulation in 3xTg-AD mice were improved by physical exercise. Facilitation and depression of field EPSPs evoked by paired-pulse stimulation of the CA1-medial prefrontal synapse at different intensities and inter-pulse intervals, and the ratio between the field EPSP amplitudes evoked by both pulses. A-C) A three-dimensional representation of data corresponding to field EPSPs evoked by the 1st (A) and the 2nd (B) pulses for NonTg mice, and the facilitation of the 2nd pulse represented by the ratio (C). A similar set of data corresponding to field EPSP evoked in 3xTg-AD (D-F) and 3xTg-AD EXE (G-I) animals is also illustrated. Note that $3 \times T g-A D$ mice showed larger field EPSP amplitudes than NonTg animals, suggesting over-activation of the CA1-medial prefrontal synapse, partially attenuated in 3xTg-AD EXE animals. Values are expresed as mean. Statistics: One-way ANOVA followed by post hoc Bonferroni's test. Significant differences between groups, when compared data of equal inter stimulus interval and equal intensity of the stimulus, are showed. Symbols indicated differences of any of both transgenic groups with respect to NonTg $(*)$ or with respect to Tg EXE (\#). One symbol: $p<0.05$; two: $p<0.01$; three: $p<0.001$.

AD animals differed from that evoked in the NonTg group and that this effect was attenuated in 3xTg-AD EXE animals, mainly in relation to peak field EPSP amplitudes following the 1st and 2nd pulses.
Exercise weakly protected the impairment of LTP induction

In contrast with the evolution of LTP evoked in alert behaving mice at the CA3-CA1 synapse [45], LTP 


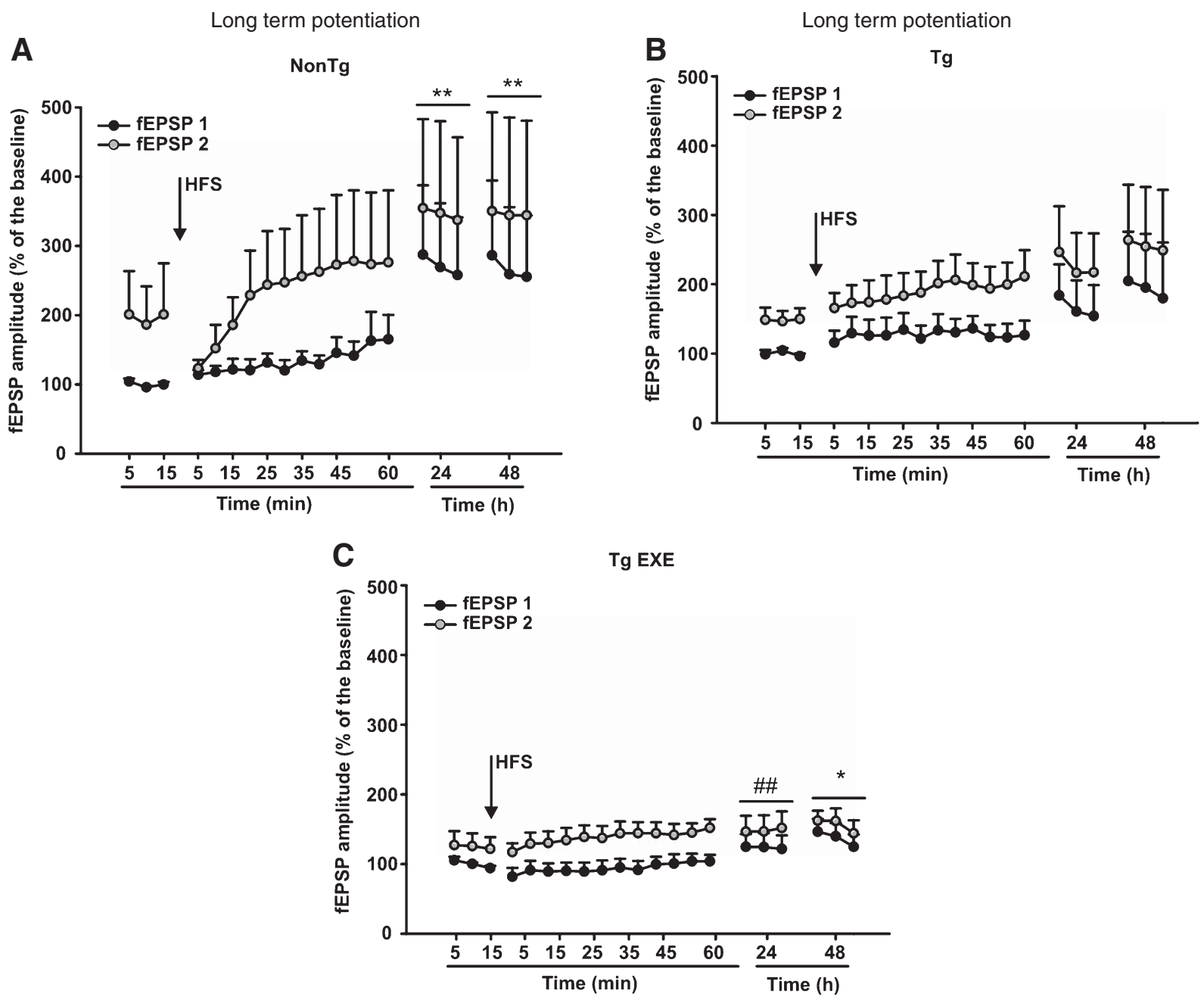

Fig. 8. Long-term potentiation was impaired in the 3xTg-AD mice. Long-term potentiation (LTP) evoked in the medial prefrontal cortex following a high-frequency stimulation (HFS) session presented to the ipsilateral hippocampal CA1 area. The amplitude of field EPSPs evoked by a pair of pulses (100 ms interval) in NonTg (A), 3xTg-AD (B) and 3xTg-AD EXE (C) mice is represented as the percentage of the baseline $(100 \%)$ value. To obtain a baseline, animals were stimulated every $20 \mathrm{~s}$ for 15 min. After HFS, the same pairs of stimuli were presented at the same rate $(3 / \mathrm{min})$ for $1 \mathrm{~h}$. Recording sessions were repeated $(15 \mathrm{~min})$ for two additional days. Exercise treatment induced a weak beneficial effect by recovering potentiation at $48 \mathrm{~h}$ after LTP induction. Values are expressed as mean \pm SEM. Statistics: One-way ANOVA followed post hoc tests. Significant (Dunnett's test) differences with respect to baseline values of each group are indicated: ${ }^{*} p<0.05$, ${ }^{*} p<0.01$. Significant (post hoc Bonferroni's test) differences with respect to the NonTg group are also indicated: \#\# $p<0.01$.

evoked at the CA1-medial prefrontal cortex synapse in NonTg mice demonstrated a slow build-up and only a small change in the amplitude of evoked field EPSPs (Fig. 8A). Thus, the LTP evoked in NonTg mice reached values significantly larger (determined by the amplitude of the field EPSPs evoked by the 1st pulse) than those collected during baseline recordings 24 and $48 \mathrm{~h}$ after the HFS session $\left[\approx 150 \%, \mathrm{~F}_{(14,140)}=2.18\right.$; $p<0.05]$. In contrast, field EPSPs evoked by the 2 nd pulses did not reach significant values. As shown in
Fig. 8B and $\mathrm{C}$, the HFS applied to $3 \mathrm{xTg}-\mathrm{AD}$ and $3 \times T g-A D$ EXE animals had an attenuated effect. Nevertheless, field EPSP amplitudes corresponding to the first pulse were significantly different from the baseline $48 \mathrm{~h}$ after induction in 3xTg-AD EXE animals $\left[\mathrm{F}_{(14,153)}=2.39, p<0.01\right]$. When compared between groups, the LTP evoked in NonTg mice by the 1st pulse was significantly larger than the values collected from the 3xTg-AD EXE mice $24 \mathrm{~h}$ after the HFS session $(p<0.005)$. Therefore, $3 \times \mathrm{Tg}-\mathrm{AD}$ animals failed to pro- 
duce any LTP at the CA1-medial prefrontal synapse following HFS, whereas 3xTg-AD EXE mice presented a weak, but significant, potentiation $48 \mathrm{~h}$ after LTP induction.

\section{Physical exercise did not significantly modify brain pathology and amyloid levels}

Immunoreactivity for $A \beta$ and phospho-tau was observed in the amygdala tissue of 4-month-old 3xTgAD mice (Fig. 9A), but was only faintly detected in the cortex and hippocampal tissue (not shown). Such light staining may be associated with the cross-reaction of the antibodies with human A $\beta P P$ and tau, respectively (see Metrials and methods). No staining differences were observed between sedentary and exercised animals. In 7-month-old 3xTg-AD mice, the CA1 subfield of the hippocampus, parietal cortex and amygdala showed obvious A $\beta$ (Fig. 9B) and phospho-tau accumulation (Fig. 9C). Females showed slightly higher $\mathrm{A} \beta$ staining in the pyramidal cortical neurons than males and also somewhat higher phospho-tau staining in the amygdala. However, no overt qualitative differences were observed between sedentary and exercised animals.
The levels of $A \beta_{40}$ and $A \beta_{42}$ and the $A \beta_{42 / 40}$ ratio were determined in the hippocampus of 4-monthold (Fig. 10A-C) and 7-month-old 3xTg-AD mice (Fig. 10D-F). Two-way ANOVA showed an effect of factor 'gender' in $A \beta_{40}$ levels at both ages tested and in $A \beta_{42 / 40}$ ratio in 7-month-old mice [all F's $>10.49$, $p<0.0102$ ] and an effect of factor 'exercise' in A $\beta_{40}$ levels at both ages tested [all F's $>5.484, p<0.0373$ ]. Females of both ages had higher levels of $A \beta_{40}$ than males and similar levels of $A \beta_{42}$. One month of exercise reduced $A \beta_{40}$ levels in 4-month-old male mice, whereas the small decreases in $A \beta_{40}$ and $A \beta_{42}$ in females were not statistically significant. Six months of exercise induced an increase of $A \beta_{40}$ in 7-monthold females. The $A \beta_{42 / 40}$ ratio was not modified by the exercise patterns analyzed in this study.

\section{Exercise exerted beneficial effects on the redox brain status of $3 x T g-A D$ mice}

The results obtained on the cerebral cortical parameters of oxidative stress are shown in Fig. 11.

\section{Exercise reduced lipid peroxidation}

Male and female 3xTg-AD had higher LPO brain cortex levels than NonTg mice at 7 months of age but
A
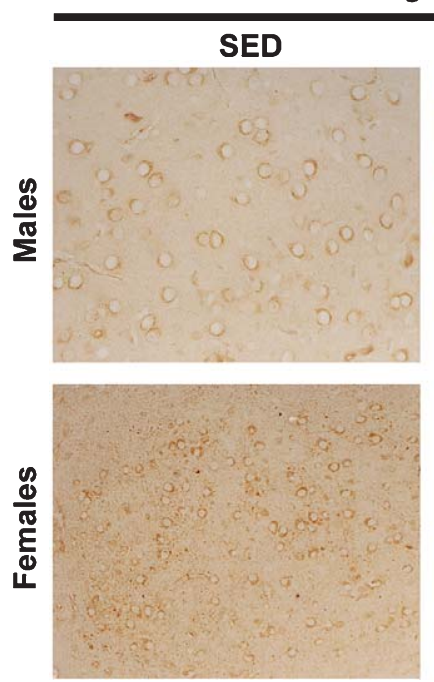

Amyloid- $\beta$
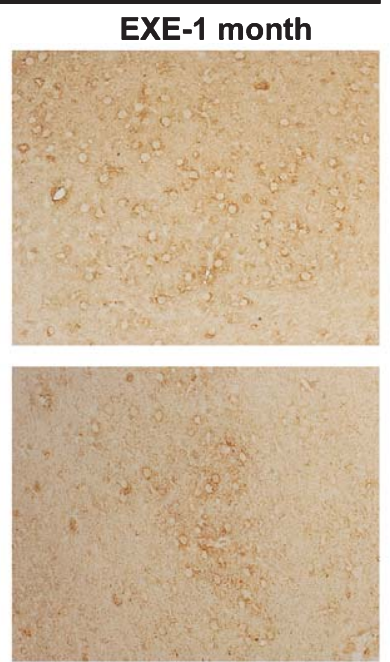

Phospho-Tau
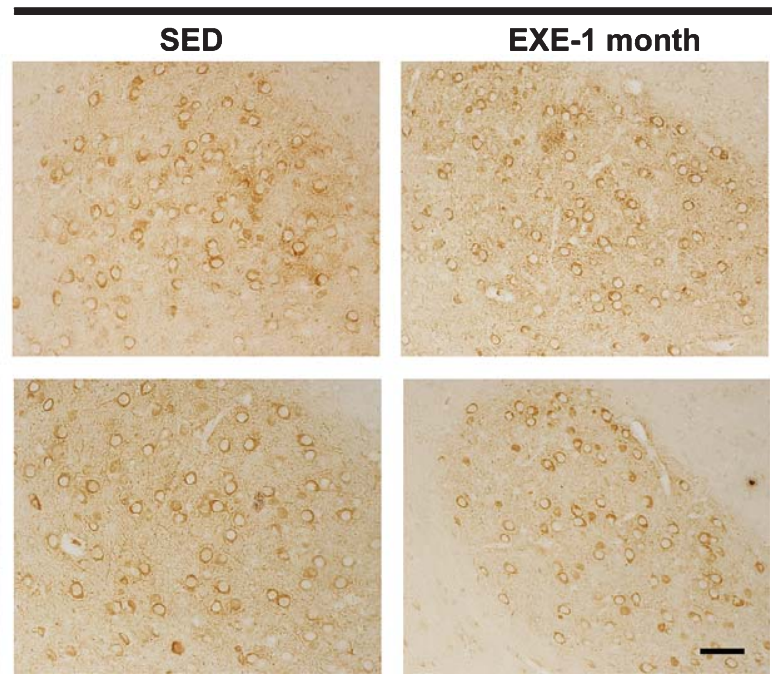

Fig. 9. Brain pathology in sedentary male and female $3 x T g-A D$ mice (SED) was not significantly reduced by voluntary running wheel exercise, either after 1 month (EXE-1 month) or 6 months of treatment (EXE-6 month). A) Representative microphotographs of basolateral amygdala of 4-month-old mice showing amyloid- $\beta$ (A $\beta$ ) and phospho-tau immunoreactivity using antibodies 4G8 and AT180, respectively. B and C) Representative microphotographs of hippocampus CA1 and basolateral amygdala of 7-month-old mice showing A $\beta$ (B) and phospho-tau immunoreactivity (C). 4G8 reacts against amino acids $1-17$ of A . AT180 detects phosphorylated tau at the threonine 321 residue. Scale bar $=20 \mu \mathrm{m}$. 


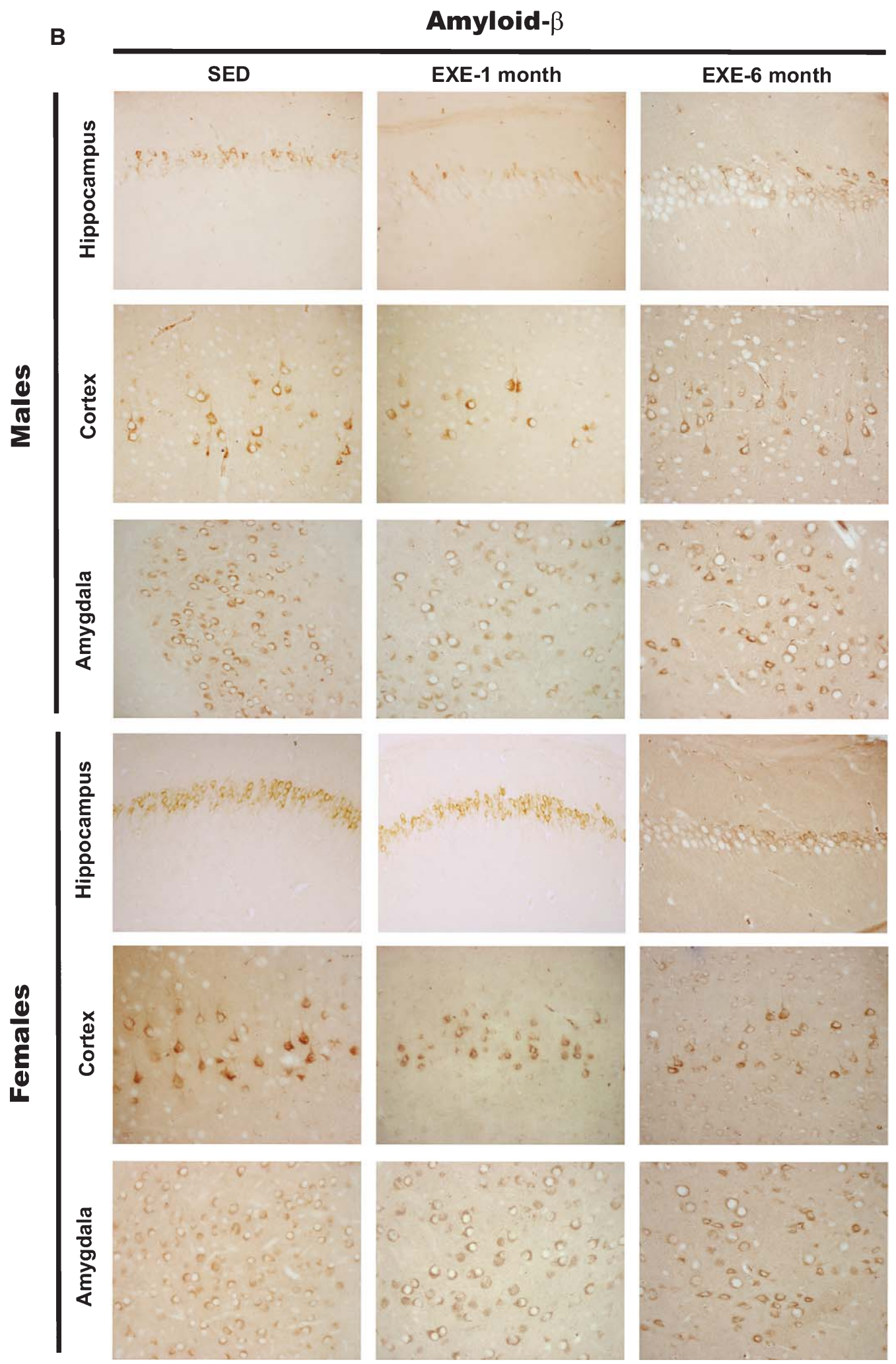

Fig. 9. (Continued) 


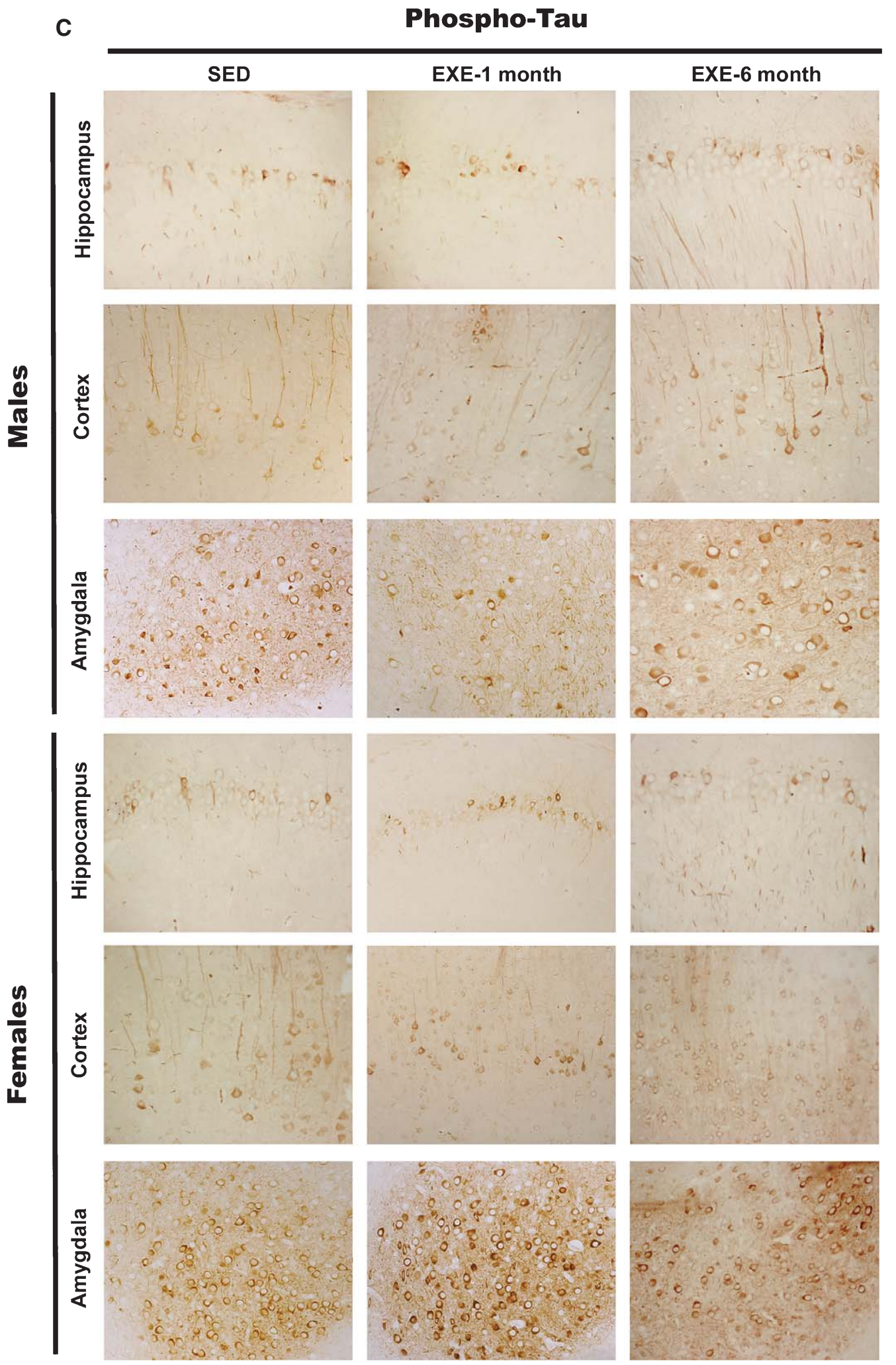

Fig. 9. (Continued) 
A

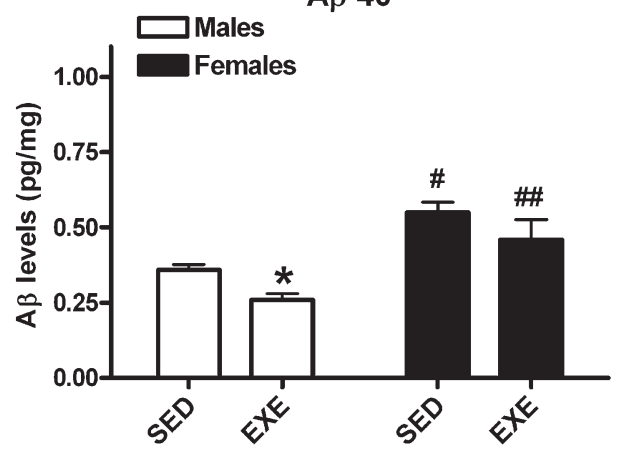

B
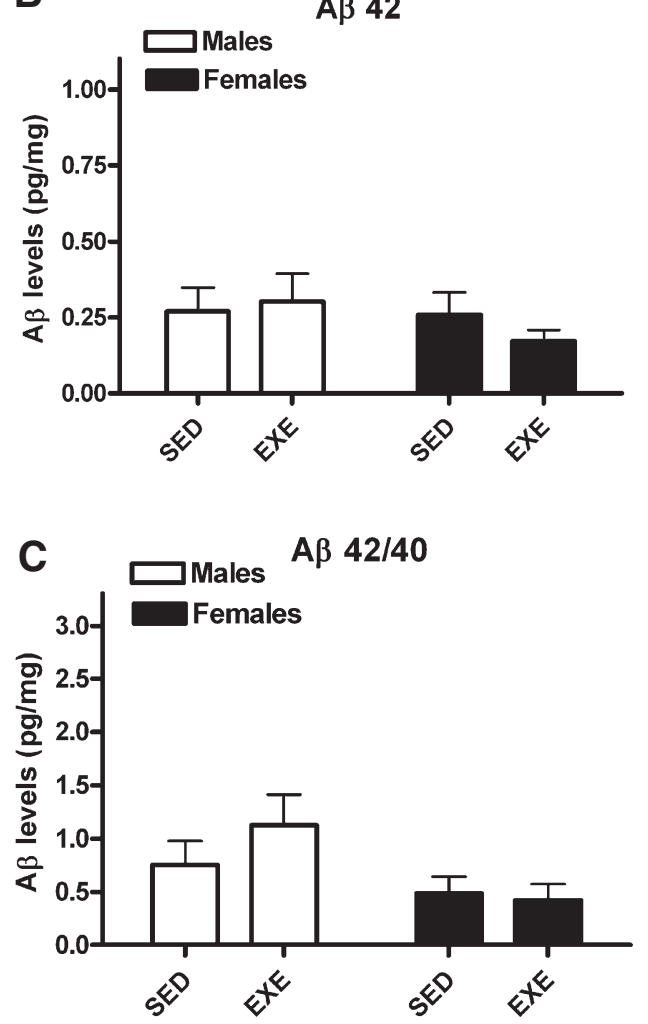

D

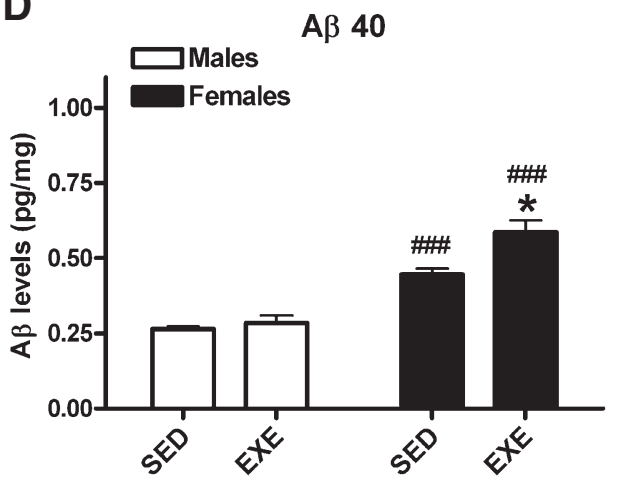

E

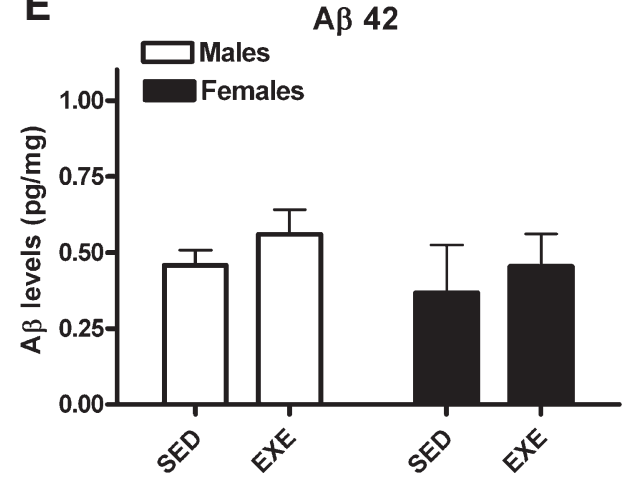

$\mathbf{F}$

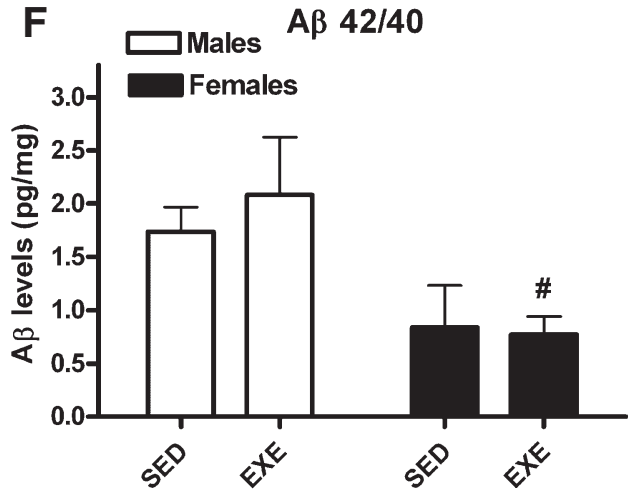

Fig. 10. Levels of soluble $\mathrm{A} \beta$ in the hippocampus of 3xTg-AD (SED) mice were not ameliorated by voluntary running wheel exercise (EXE). A-C) $A \beta_{40}(A), A \beta_{42}(B)$, and the $A \beta_{42 / 40}$ ratio (C) in 4-month-old animals after 1 month of exercise. D-F) $A \beta_{40}(D), A \beta_{42}(E)$, and $A \beta_{42 / 40}(F)$ in 7-month-old animals after 6 months of exercise. Levels of $A \beta_{40}$ and $A \beta_{42}$ were determined by sandwich ELISA. Values are the mean \pm SEM, $n=3-4$. Statistics: Two-way ANOVA followed by Bonferroni's post hoc test. Significant differences between groups: $* p<0.05$ compared to corresponding SED; ${ }^{\#} p<0.05,{ }^{\# \#} p<0.01,{ }^{\# \# \#} p<0.001$ compared to corresponding male group.

this was ameliorated by voluntary exercise (Fig. 11A, B). Short-term exercise produced the highest reduction. Two-way ANOVA showed an effect of factor 'exercise' in 7-month-old female mice $\left[\mathrm{F}_{(2,40)}=3.91\right.$, $p=0.0283]$. However, the effect of factor 'genotype' did not reach significance. Both NonTg and 3xTg-AD male mice had higher LPO levels at 7 months than at 4 months of age. Female mice did not show an age-related LPO increase.

\section{Exercise induced glutathione cycle}

Four-month-old male 3xTg-AD mice showed higher GSH levels after 1 month of exercise than NonTg mice (Fig. 11C, D). At 7 months, female NonTg 

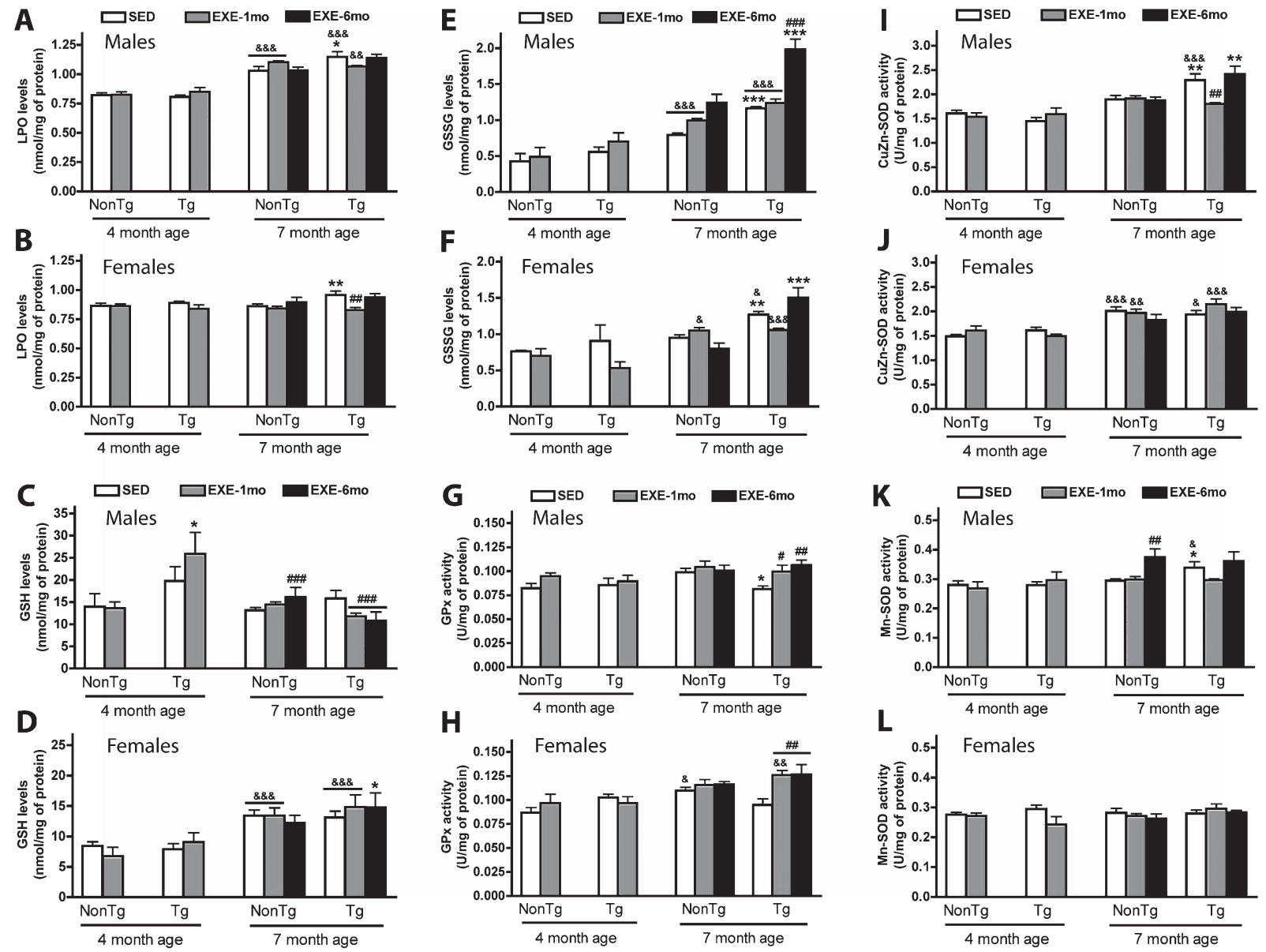

Fig. 11. Oxidative stress in the cerebral cortex of 7-month-old male and female 3xTg-AD mice, but not in 4-month-old mice was demonstrated by the alteration of most of the tested markers. Voluntary wheel running ameliorated these alterations although the beneficial effects depended on the parameter tested. A) and B) Lipid peroxidation (LPO) levels were reduced to NonTg levels. C) and D) Reduced glutathione (GSH) levels were increased in some of the experimental groups. E) and F) Oxidized glutathione (GSSG) levels were further increased by long-term exercise (6 months). G) and H) Glutathione peroxidase (GPx) enzyme was activated in the 7-month-old 3xTg-AD mice after exercise treatment. I) and J) $\mathrm{Cu} / \mathrm{Zn}$ superoxide dismutase (CuZn-SOD) enzymatic activity tended to be normalized by exercise. K) and L) Mn superoxide dismutase (Mn-SOD) enzymatic activity was only affected in males. For experimental groups see legend to Fig. 1. Data represent the mean \pm SEM of 6-10 animals, tested in duplicate. Statistics: Two-way ANOVA followed by Bonferroni's post hoc test. Significant differences between groups: $* p<0.05, * * p<0.01$, and $* * * p<0.001$, Tg mice compared to the corresponding treatment group of NonTg mice; ${ }^{\#} p<0.05$, \#\# $p<0.01$, and

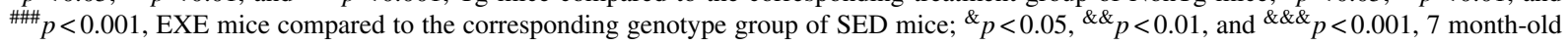
mice compared to the corresponding group of 4-month-old mice.

and 3xTg-AD mice showed higher GSH levels than at 4 months. At the older age, exercise training in males increased GSH in NonTg mice and decreased it in 3xTg-AD mice. No GSSG was detected at 4 months of age (Fig. 11E, F). Seven-month-old male and female 3xTg-AD mice had higher levels of GSSG than NonTg mice. This was exacerbated by 6 months of running wheel exercise in the male group. However, 1 month of exercise was protective in female 3xTg-AD mice. Female 3xTg-AD and male NonTg and $3 \times$ Tg-AD mice showed higher levels of GSSG at
7 months than at 4 months of age. Two-way ANOVA indicated an effect of factor 'genotype' in GSSG levels in 7-month-old males $\left[\mathrm{F}_{(1,43)}=64.81, p<0.0001\right]$ and females $\left[\mathrm{F}_{(1,40)}=37.90, p<0.0001\right]$, and an effect of factor 'exercise' only in male mice $\left[\mathrm{F}_{(2,43)}=47.21\right.$, $p<0.0001]$.

GPx activity was lower in 7-month-old 3xTg-AD mice compared to NonTg mice, although this difference was only significant in males and not in females (Fig. 11G, H). Exercise treatment increased GPx to control levels for both male and female 3xTg-AD 
mice. Seven-month-old female NonTg mice presented higher levels of GPx than the younger age group. Twoway ANOVA indicated an effect of factor 'exercise' in 7-month-old males $\left[\mathrm{F}_{(2,42)}=3.60, p=0.0361\right]$ and females $\left[\mathrm{F}_{(2,40)}=6.49, p=0.0038\right]$.

\section{Exercise partially normalized superoxide dismutase activity}

Seven-month-old male 3xTg-AD mice had higher levels of CuZn SOD and Mn SOD activities than NonTg mice (Fig. 11I, K). These effects were ameliorated by short-term but not by the longer term exercise of 6 months. However, the 6-month treatment increased CuZn SOD activity in NonTg males (Fig. 11K). Both 7-month-old NonTg and 3xTg-AD mice showed higher $\mathrm{CuZn}$ SOD than 4-month-old females (Fig. 11J). Females did not show changes in Mn SOD activity (Fig. 11L). Two-way ANOVA showed a significant effect of factor 'genotype' in $\mathrm{CuZn} \operatorname{SOD}\left[\mathrm{F}_{(1,42)}=9.58, p=0.0035\right]$ and factor 'exercise' in both CuZn SOD $\left[\mathrm{F}_{(2,42)}=4.027, p=0.0251\right]$, and Mn SOD $\left[\mathrm{F}_{(2,43)}=8.08, p=0.0011\right]$ in 7-monthold male mice.

\section{DISCUSSION}

The present study characterized the physical, behavioral, and cognitive conditions of 3xTg-AD mice in the early and moderate phases of AD-like pathology seen at 4 and 7 months of age, respectively, and the synaptic function at 7 months of age. The differential course of severity of $3 \times \mathrm{Tg}-\mathrm{AD}$ phenotype between genders confirmed previous studies [26, 29]. Increased severity in female brain pathology and in male brain oxidative stress, were detected mainly in the moderate $\mathrm{AD}$-like phase [29], but they were already present at 4 months of age. Voluntary physical exercise in the running wheel ameliorated many of the $3 \times \mathrm{Tg}$ AD pathological behaviors and brain oxidative stress changes, as discussed below. The protective effects of physical exercise against some of these phenotype alterations were also gender-specific, as previously reported for the $3 \times \mathrm{Tg}-\mathrm{AD}$ mouse $[28,29]$. The wheel running exercise also improved the physical condition of the NonTg mice. In this regard, it should be noted that the present experimental design, using both male and female, NonTg and 3xTg-AD mice, allowed the effects of physical exercise in a sedentary but otherwise healthy mouse to be discerned from the effects on $\mathrm{AD}$ pathology. Furthermore, the main novelty of the present results was the demonstration that the distur- bances in the underlying neurophysiological synaptic mechanisms in 3xTg-AD mice were partially ameliorated by physical exercise, correlating to the cognitive outcome tests.

The first part of this study focused on physical condition. The results reproduced previous findings of overweight in male $3 \times \mathrm{Tg}$-AD mice from the Spanish colony [24, 29]. Overweight was present at 4 months and 7 months of age. Male 3xTg-AD weight reverted to the NonTg weight only after the 6-month exercise treatment. Interestingly, all 3xTg-AD mice were more active in the running wheel during the first month of exercise than NonTg mice, but this did not lead to body weight normalization. The decrease in body weight of male 3xTg-AD mice required long-term exposure to wheel running, which probably restored metabolic derangements, such as the glucose intolerance found in $3 \times T g-A D$ mice $[29,51]$ and the leptin-pathway impairment discovered in other AD transgenic mouse models (Tg2576 [52] and TgCRND8 [53]). Indeed, it is known that there is a complex link between physical activity and body weight change due to modulation by the mouse strain genes [54]. In sedentary conditions both genders of $3 \times \mathrm{Tg}-\mathrm{AD}$ had a better sensorimotor profile than NonTg mice, as a characteristic of this mouse colony at early stages [29]. Indeed, the appearance of deficiencies in the $3 \times \mathrm{Tg}-\mathrm{AD}$ sensorial tests is not expected until advanced AD pathology stages are reached $[24,25]$. The higher muscular strength and coordination may be related to the higher motivation for voluntary physical exercise of $3 \times \mathrm{Tg}-\mathrm{AD}$ mice as compared to NonTg mice. This commitment of 3xTg-AD mice to 'running' behavior was not seen in a previous study in a treadmill, in which the anxiety component triggered by forced exercise should be considered [29]. Sensorimotor responses were improved by both short-term and long-term wheel exercise in 3xTg-AD mice of both ages. As regards to NonTg mice, exercise treatment reduced the body weight of the 7-month-old mice as related to the sedentary ones, this in agreement with an increased body fitness effect. However, sensorimotor beneficial effects were detected in the younger but not in older NonTg mice, suggesting that 7-month-old NonTg mice had already completed their sensorimotor development. Accordingly, the later mice increased their 'running' behavior up to the $3 \times \mathrm{Tg}$-AD levels in the long training period.

The assays that were carried out to analyze BPSDlike behaviors indicated an increase in these behaviors in both 4- and 7-month-old 3xTg-AD mice compared to NonTg mice, with age- and gender-related effects, in agreement with previous reports on the $3 \times \mathrm{Tg}-\mathrm{AD}$ 
phenotype [24, 25, 29, 35]. The results showed young male and female $3 \times$ Tg-AD neophobia (corner test) and female freezing behavior and reduced deambulation and exploration in a new environment (open field test). In the older age group, female freezing behavior and reduced deambulation (open field test), anxiety-mediated responses (dark and light box test), and reduced exploratory behavior (hole-board test) by both genders were strong components in the behavior of $3 \times \mathrm{Tg}-\mathrm{AD}$ mice. Running wheel exercise alleviated most of these symptoms. The best outcome was obtained following 6 months of exercise in 7-monthold males and females, which achieved NonTg levels of anxiety and willingness to explore. This treatment however did not ameliorate the reduced motor activity observed in the open field test using $3 \times \mathrm{Tg}-\mathrm{AD}$ mice, as previously reported for a 3-month running wheel treatment [28]. Increased startle reflexes in $3 \times \mathrm{Tg}$ $\mathrm{AD}$ female mice have previously been suggested on the basis of subjective observational neuroassessment [25], which would be consistent with the presence of the above discussed BPSD-like behaviors. We thus carried out general startle response and subsequent prepulse inhibition assays in the sedentary and 6month exercise groups of $3 \times \mathrm{Tg}$-AD male mice. The assays confirmed a sensorimotor gating dysfunction in $3 x \mathrm{Tg}-\mathrm{AD}$ mice, but unfortunately they were only partially protected by the exercise treatment. Sensorimotor gating processes have been widely studied in schizophrenia and psychotic disorders [39], but decreased prepulse inhibition responses have also been reported in other AD mouse models (AßPP751SL and PS1M146L and their double mutant A $\beta P P / P S 1$ [55]). The involvement of sensorimotor cortical circuits in these gating processes does not rule out the possibility that the subsequent abnormal attention to new information affects cognitive ability [56]. In general, changes induced by voluntary exercise in the BPSD-like profile of NonTg mice were negligible.

The cognitive abilities of 3xTg-AD mice have previously been extensively analyzed using the MWM test. It has been reported that during the moderate AD-like pathology period of 6-7 months of age both genders show mild spatial deficits [24, 26, 57], but female mice show greater deficiences in the retention of learning [26]. In addition to hippocampal-dependent spatial learning and memory in the MWM, the $3 \times \mathrm{Tg}$ AD phenotype has also shown deficiences in emotional learning and memory assessed using the passiveavoidance test [26]. As expected, the present results showed 3xTg-AD deficiences in the retention of learning in the MWM of 7-month-old male and female mice and 4-month-old female mice. Even retention testing in 4-month-old males showed a tendency to discern 3xTg-AD from NonTg responses, but the latter presented high variability that precluded to obtaining significant results. The protective effect of voluntary physical exercise against memory lost was remarkable in females and in the older tested males. The longterm exercise training induced the best recovery in the 7-month-old 3xTg-AD mice. Previous studies have also shown a positive effect on MWM spatial memory of 3-month wheel running in 3xTg-AD mice [28] and 3 -weeks of running in the aged $\operatorname{Tg} 2576$ mouse model of $\mathrm{AD}$ [58]. On the other hand, 4 months of voluntary wheel but not forced treadmill exercise has been reported to improve memory in the object recognition test in 9-month-old Tg2576 mice [30]. No improvement in the MWM has been reported in 6-month-old 3xTg-AD mice after 1 month of treadmill exercise [29]. Taken together, this results confirm that voluntary physical exercise is a good intervention for cognitive improvement from AD neuropathology whereas forced exercise may be too stressful for the mice. In this regard, MWM testing itself may be stressful because mice are terrestrial animals, and thus an alternative cognitive test would complement the MWM results on the protection gained from physical exercise. The novel-object recognition assays which evaluate hippocampal-dependent nonspatial learning and memory [59] cannot be used because test-linked deficiences appear at advanced pathological stages in $3 \times T g-A D$ mice [26]. Therefore, we tested the instrumental (operant) conditioning behavior with positive reinforcement in the Skinner box. During instrumental conditioning the animal learns the consequences of their own actions. This is a complex behavior that involves the striatum and amydgala and the underlying circuitry and mechanisms are poorly understood [60]. Male 3xTg-AD mice at 7-months of age showed impaired behavior, and it was noted that neurons in the amygdala were visibly stained with anti-A $\beta$ and phospho-tau antibodies in these animals. Physical exercise improved the instrumental conditioned behavior of 3xTg-AD mice, further demonstrating the beneficial effect of nonstressful chronic exercise training in learning and memory pathways. Instrumental conditioning acquisition was also impaired in the AßPP751SL mouse model of AD at 5-6 months of age [61].

The neurophysiological experiments carried out in this study showed severe disturbances of synaptic plasticity in freely behaving 7-month-old 3xTg-AD male mice. The $3 \times \mathrm{Tg}-\mathrm{AD}$ animals failed to produce any LTP at the CA1-medial prefrontal cortex synapse. 
This result confirmed the previously reported LTP deficiencies observed in hippocampal slices of 6month-old 3xTg-AD mice [22]. Thus, LTP deficiency correlated with the intraneuronal accumulation of $A \beta$ and phospho-tau in the CA1 pyramidal neurons and appeared well in advance of plaque and tangle formation. In other AD transgenic models, reduced LTP also appears in advance of plaque formation (i.e., $\mathrm{TgA \beta PP} / \mathrm{Ld} / 2$ [44], Tg2576 [62]) or rather correlates with hippocampal CA1 cell loss (i.e., TgAßPP (C104) [63], TgPDAßPP [64]). In other mouse strains impairment of the LTP appears at an older age (i.e., TgAßPP695swe [65], TgAßPPPS1-21 [66]). Therefore, mechanisms other than $A \beta$ plaques may be involved in synapse impairment in the diverse $\mathrm{AD}$ mouse models. In this regard, synaptic and cognitive deterioration may be partially related to deterioration in brain age itself [55]. Indeed the nontransgenic mouse model of accelerated senescence SAMP8 [67], which has traits of AD [68], was recently reported to present LTP and cognitive deficiencies at the early age of 5 months (López-Ramos et al., unpublished results). The tridimensional characterization of synaptic transmission (input/ouput parameters) showed a differential pattern for $3 \mathrm{xTg}-\mathrm{AD}$ compared to the NonTg mouse. The general overactivation in the CA1-medial prefrontal cortex synapse was indicative of the alterations in brain circuitry at this moderate pathological stage (7-month-old). Such alterations may be induced as a compensatory change or may comprise an excitotoxicity process that will lead to further neural failure. On the other hand, no significant changes in paired pulse facilitation were present, in agreement with previous results in hippocampal slices [22]. Changes in paired-pulse plasticity have been reported for other AD mouse models, either enhanced paired-pulse facilitation (i.e., TgPDA $\beta P P$ [64], PS1-KI [22]) or deficits (i.e., TgA $\beta P P / L d / 2$ [44], TgAßPPPS1-21 [66], TgPS2A $\beta P P$ [69]). In the latter mice, paired-pulse facilitation deficits, indicative of loss of short-term synaptic plasticity, occur at an advanced age/pathological stage. Physical exercise reduced the changes in synaptic transmission in $3 \times \mathrm{Tg}$ $\mathrm{AD}$ mice almost to control values.

With regards to LTP recovery, the impact of treatment on LTP recovery was poor. However, the minimal restoration of long-term plasticity in the CA1-prefontal cortex synapse was probably combined with the recovery of the other hippocampal pathways, helping in the cognitive recovery in the learning and memory tests.With regards to neuropathological aspects, it is known that $3 \mathrm{xTg}-\mathrm{AD}$ mice develop intraneuronal $\mathrm{A} \beta$ as a characteristic pathological feature of this $\mathrm{AD}$ mouse model, and that this precedes tau pathology, amyloid plaques, and finally tangle formation [22, $23,70]$. Intracellular $A \beta_{42}$ has been detected as early as 2 months of age [71]. Accordingly, light $A \beta$ and phospho-tau deposits were observed in the amygdala (basolateral nucleus) of 4-month-old 3xTg-AD mice and in all three analyzed brain areas (amygdala, temporal cortex and CA1 hippocampus) of the 7-month-old $3 \times T g-A D$ mice. Brain cortical $A \beta$ deposits appeared slightly larger in females than in males, in agreement with previous observations in this mouse [28, 29]. The exercise paradigm used did not ameliorate $A \beta$ deposits or PHF-tau pathology. Studies of voluntary wheel running exercise performed in other transgenic mouse models of $\mathrm{AD}$ have reported variable results, either a decrease in plaque formation in TgCRND8 [72] and $\operatorname{Tg} 2576$ [30] after 4-5 months, or no changes in AßPP23 [73] and TgCRND8 [74] after a shorter period of exercise. Levels of $A \beta_{40}$ were higher in female $3 \times \mathrm{Tg}-\mathrm{AD}$ mice than in males as previously reported [29], in agreement with the above mentioned pathological and behavioral signs observed in female $3 \times \mathrm{Tg}-\mathrm{AD}$ mice. The voluntary exercise patterns assayed did not improve the $A \beta$ hippocampus levels in agreement with the immunohistochemistry results. Other authors have reported some amelioration of brain $A \beta$ content by wheel running exercise in old transgenic A $\beta P P 23$ [73] and Tg2576 [75] AD mice. However, we should take into account that $3 \times \mathrm{Tg}-\mathrm{AD}$ mice did not show $\mathrm{A} \beta$ plaques at the tested ages of 4 and 7 months, and it appears that plaques are more sensitive to exercise treatment than intracellular $\mathrm{A} \beta$.

In addition to the previously discussed pathology, the $3 \times$ Tg-AD mouse also models the oxidative stress shown in the AD brain, as reported in females at an early age of 3-5 months [76] and in both genders at 7 months [29]. In the present study, 4-month-old $3 \times \mathrm{Tg}$-AD mice showed negligible changes in oxidative stress. However both genders of 7-month-old 3xTg$\mathrm{AD}$ mice showed an increase in oxidation products (lipid peroxidation products and GSSG molecules) and changes in antioxidant enzyme activities compared to NonTg mice. In general, less oxidative-related changes were detected in female than in male $3 x T g-A D$ mice. Males were more prone to oxidative stress than females, as were 7-month-old NonTg males, which had higher oxidative stress parameters than the 4-monthold mice. It is known that the antioxidant effect of estradiol [77] may underly the lower oxidative stress levels in females compared to males in several animal species. Wheel running exercise partially maintained 
redox homeostasis by increasing GSH and/or mitochondrial SOD in conditions of moderate oxidative stress (male NonTg and female 3xTg-AD) and increasing GPx in more stressful conditions (both genders $3 x$ Tg-AD). Similar attenuation of oxidative changes have been reported after treadmill treatment in 7month-old 3xTg-AD mice [29]. Nonetheless, GSSG levels of 3xTg-AD mouse brain after 6 months of wheel running were high. This molecule may be involved in the activation of the GSH cycle and increase in antioxidant defence induced by exercise.

In summary, this study extended previous characterization of the $3 \times \mathrm{Tg}-\mathrm{AD}$ mouse by studying a wide range of brain functions in vivo (from synapse function to the acquisition of decision-making behavior) and ex vivo (oxidative stress and amyloid and tau pathology) and unveiled some of the mechanisms underlying the neuroprotective effect of physical exercise against AD. Voluntary physical exercise in a freely available running wheel demonstrated a neuroprotective effect against cognitive and BPSD-like disturbances in the mouse behavior that can be translated in humans as memory loss, anxiety, depression, lack of motivation, and apathy, some of the main problems in the AD patient [78-80]. Male and female 3xTg-AD mice showed differential progression of the pathological phenotype, in agreement with previous reports [24, $26,59]$, but both benefited from physical exercise. The different temporal patterns analyzed showed that the longer treatment, from 1 to 7 months of age, gave the best outcome in terms of improvement of cognition and BSPD-like behavior. With regards to the underlying mechanisms, no amelioration of $A \beta$ and phospho-tau pathology was detected, but the improvement in oxidative stress brain status and positive effects on synaptic function and plasticity were significant. This is consistent with a non-AD specific protective effect of physical exercise against AD-like pathology in the 3xTg-AD brain. Exercise has a direct effect on synapse structure and strength and an indirect effect through promoting neurogenesis, neurotrophic factor signaling and metabolic and vascular brain function $[19,20]$, leading to the observed improvement in the synaptic function improvement found. In addition, exercise has many general systemic effects that also improve brain health, such as the regulation of inflammation, growth factor secretion and insulin signaling [20], these being easier to test at advanced pathological stages. The beneficial effects on synapse and neurotransmission mediated through an improvement in redox homeostasis were not at all negligible. Oxidative stress is a biochemical hallmark in AD and it has been suggested to form a link between aging and $\mathrm{AD}[38$, 81]. Regular exercise increases the brain's defenses against oxidative stress [17] and hence protects against AD-related oxidative stress [18]. In this regard, physical exercise would be more effective than antioxidant drugs because it acts on multiple targets. The healthy NonTg mice showed increased antioxidant defense in brain after the training, in addition to the above mentioned improved sensorimotor performance and body fitness. Therefore, chronic physical exercise protects against and/or delays AD-like pathological behaviors in the $3 \mathrm{xTg}$-AD mouse and is recommended in humans to help prevent $\mathrm{AD}$.

\section{ACKNOWLEDGMENTS}

This study was supported by grants SAF200613092-C02-02 and SAF2009-13093-C02-02 from the Spanish Ministerio de Ciencia e Innovación (MCINN), RD06/0013/0003, RD06/0013/1004 RD06/0013/1015 and DPS2008/0692 from Instituto de Salud Carlos III, Spain, and 2009/SGR/214 from the Generalitat and 062930 and 062931 from the Fundació La Marató de TV3, Catalonia. Yoelvis García-Mesa acknowledges support from the Fundació La Marató de TV3; Susana Revilla acknowledges support from FPU, MCINN. We thank Jèssica López Regal; Jofre Serret and Albert Parull for their skilful technical assistance.

Authors' disclosures available online (http://www.jalz.com/disclosures/view.php?id=704).

\section{REFERENCES}

[1] Bennett DA (2000) Part II. Clinical diagnosis and course of Alzheimer's disease. Dis Month 10, 666-687.

[2] Jicha GA, Carr SA (2010) Conceptual evolution in Alzheimer's disease: implications for understanding the clinical phenotype of progressive neurodegenerative disease. $J$ Alzheimers Dis 19, 253-272.

[3] Selkoe DJ (2002) Alzheimer's disease is a synaptic failure. Science 298, 789-791.

[4] Castellani RJ, Lee HG, Siedlak SL, Nunomura A, Hayashi T, Nakamura M, Zhu X, Perry G, Smith MA (2009) Reexamining Alzheimer's disease: evidence for a protective role for amyloid-beta protein precursor and amyloid-beta. $J$ Alzheimers Dis 18, 447-452.

[5] Querfurth HW, LaFerla FM (2010) Alzheimer's disease. $N$ Engl J Med 362, 329-344.

[6] Sabbagh MN (2009) Drug development for Alzheimer's disease: where are we now and where are we headed? Am J Geriatr Pharmacother 7, 167-185.

[7] Brookmeyer R, Johnson E, Ziegler-Graham K, Arrighi HM (2007) Forecasting the global burden of Alzheimer's disease. Alzheimers Dement 3, 186-191. 
[8] Pope SK, Shue VM, Beck C (2003) Will a healthy lifestyle help prevent Alzheimer's disease? Annu Rev Public Health 24, 111-132.

[9] Warburton DE, Nicol CW, Bredin SS (2006) Health benefits of physical activity: the evidence. CMAJ 174, 801-809.

[10] Barbour KA, Blumenthal JA (2005) Exercise training and depression in older adults. Neurobiol Aging 26(Suppl. 1), 119-123.

[11] Larson EB, Wang L, Bowen JD, McCormick WC, Teri L, Crane P, Kukull W (2006) Exercise is associated with reduced risk for incident dementia among persons 65 years of age and older. Ann Intern Med 144, 73-81.

[12] Lautenschlager NT, Cox KL, Flicker L, Foster JK, van Bockxmeer FM, Xiao J, Greenop KR, Almeida OP (2008) Effect of physical activity on cognitive function in older adults at risk for Alzheimer disease: a randomized trial. JAMA 300, 1027-1037.

[13] Baker LD, Frank LL, Foster-Schubert K, Green PS, Wilkinson CW, McTiernan A, Plymate SR, Fishel MA, Watson GS, Cholerton BA, Duncan GE, Mehta PD, Craft S (2010) Effects of aerobic exercise on mild cognitive impairment: a controlled trial. Arch Neurol 67, 71-79.

[14] Williams CL, Tappen RM (2007) Effect of exercise on mood in nursing home residents with Alzheimer's disease. Am J Alzheimers Dis Other Demen 22, 389-397.

[15] Teri L, Gibbons LE, McCurry SM, Logsdon RG, Buchner DM, Barlow WE, Kukull WA, LaCroix AZ, McCormick W, Larson EB (2003) Exercise plus behavioral management in patients with Alzheimer disease: a randomized controlled trial. JAMA 290, 2015-2022.

[16] Williams CL, Tappen RM (2008) Exercise training for depressed older adults with Alzheimer's disease. Aging Ment Health 12, 72-80.

[17] Radak Z, Chung HY, Goto S (2008) Systemic adaptation to oxidative challenge induced by regular exercise. Free Radic Biol Med 44, 153-159.

[18] Radak Z, Hart N, Sarga L, Koltai E, Atalay M, Ohno H, Boldogh I (2010) Exercise plays a preventive role against Alzheimer's disease. J Alzheimers Dis 20, 777-783.

[19] Cotman CW, Berchtold NC (2002) Exercise: a behavioral intervention to enhance brain health and plasticity. Trends Neurosci 25, 295-301.

[20] Cotman CW, Berchtold NC, Christi LA (2007) Exercise builds brain health: key roles of growth factor cascades and inflammation. Trends Neurosci 30, 464-472.

[21] van Praag H (2009) Exercise and the brain: something to chew on. Trends Neurosci 32, 283-290.

[22] Oddo S, Caccamo A, Shepherd JD, Murphy MP, Golde TE, Kayed R, Metherate R, Mattson MP, Akbar Y, LaFerla FM (2003) Triple-transgenic model of Alzheimer's disease with plaques and tangles: intracellular $\mathrm{Ab}$ and synaptic dysfunction. Neuron 39, 409-421.

[23] Oddo S, Caccamo A, Kitazawa M, Tseng BP, LaFerla FM (2003) Amyloid deposition precedes tangle formation in a triple transgenic model of Alzheimer's disease. Neurobiol Aging 24, 1063-1070.

[24] Giménez-Llort L, Blázquez G, Cañete T, Johansson B, Oddo S, Tobeña A, LaFerla FM, Fernández-Teruel A (2007) Modeling behavioral and neuronal symptoms of Alzheimer's disease in mice: a role for intraneuronal amyloid. Neurosci Biobehav Rev 31, 125-147.

[25] Sterniczuk R, Antle MC, LaFerla FM, Dyck RH (2010) Characterization of the 3xTg-AD mouse model of Alzheimer's disease: part 2. Behavioral and cognitive changes. Brain Res 1348, 149-155.
[26] Clinton LK, Billings LM, Green KN, Caccamo A, Ngo J, Oddo S, McGaugh JL, LaFerla FM (2007) Age-dependent sexual dimorphism in cognition and stress response in the 3xTg-AD mice. Neurobiol Dis 28, 76-82.

[27] Giménez-Llort L, Arranz L, Maté I, de la Fuente M (2008) Gender-specific neuroimmunoendocrine aging in a tripletransgenic 3xTg-AD mouse model for Alzheimer's disease and its relation with longevity. Neuroimmunomodulation $\mathbf{1 5}$, 331-343.

[28] Pietropaolo S, Sun Y, Li R, Brana C, Feldon J, Yee BK (2008) The impact of voluntary exercise on mental health in rodents: a neuroplasticity perspective. Behav Brain Res $\mathbf{1 9 2}$, 42-60.

[29] Giménez-Llort L, García Y, Buccquieri K, Revilla S, Suñol C, Cristofol R, Sanfeliu C (2010) Gender-specific neuroimmunoendocrine response to treadmill exercise in $3 \times \mathrm{Tg}-\mathrm{AD}$ mice. Int J Alzheimers Dis 2010, 17 pp. doi:10.4061/2010/128354

[30] Yuede CM, Zimmerman SD, Dong H, Kling MJ, Bero AW, Holtzman DM, Timson BF, Csernansky JG (2009) Effects of voluntary and forced exercise on plaque deposition, hippocampal volume, and behavior in the Tg2576 mouse model of Alzheimer's disease. Neurobiol Dis 5, 426-432.

[31] Madroñal N, Gruart A, Delgado-García JM (2009) Differing presynaptic contributions to LTP and associative learning in behaving mice. Front Behav Neurosci 3, 1-14.

[32] Bliss TV, Lomo T (1973) Long-lasting potentiation of synaptic transmission in the dentate area of the anaesthetized rabbit following stimulation of the perforant path. J Physiol 232, 331-356.

[33] Delgado-García JM, Gruart A (2008) An experimental model for the study of cognitive disorders: the hippocampus and associative learning in mice. Neurotox Res 14, 359-366.

[34] Jay TM, Burette F, Laroche S (1996) Plasticity of the hippocampal-prefrontal cortex synapses. J Physiol Paris 90, 361-366.

[35] Giménez-Llort L, Blázquez G, Cañete T, Rosa R, Vivó M, Oddo S, Navarro X, LaFerla FM, Johansson B, Tobeña A, Fernández-Teruel A (2006) Modeling neuropsychiatric symptoms of Alzheimer's disease dementia in 3xTg-AD mice. In Alzheimer's Disease: New Advances, Iqbal K, Winblad B, Avila J. Medimond SRL, eds, Pianoro (BO), Italy, pp. 513516.

[36] Meziane H, Ouagazzal AM, Aubert L, Wietrzych M, Krezel W (2007) Estrous cycle effects on behavior of C57BL/6J and BALB/cByJ female mice: implications for phenotyping strategies. Genes Brain Behav 6, 192-200.

[37] Morris R (1984) Development of a water-maze procedure for studying spatial learning in the rat. J Neurosci Methods 11, 47-60.

[38] García-Matas S, de Vera N, Ortega-Aznar A, Marimon JM, Adell A, Planas AM, Cristòfol R, Sanfeliu C (2010) In vitro and in vivo activation of astrocytes by amyloid-beta is potentiated by pro-oxidant agents. J Alzheimers Dis 20, 229-245.

[39] Borrell J, Vela JM, Arévalo-Martin A, Molina-Holgado E, Guaza C (2002) Prenatal immune challenge disrupts sensorimotor gating in adult rats: implications for the etiopathogenesis of schizophrenia. Neuropsychopharmacology 26, 204-215.

[40] Gottlieb M, Leal-Campanario R, Campos-Esparza MR, Sánchez-Gómez MV, Alberdi E, Arranz A, DelgadoGarcía JM, Gruart A, Matute C (2006) Neuroprotection by two polyphenols following excitotoxicity and experimental ischemia. Neurobiol Dis 23, 374-386.

[41] Eleore L, López-Ramos JC, Yi P, Delgado-García JM (2007) The cognitive enhancer T-588 partially compen- 
sates the motor associative learning impairments induced by scopolamine injection in mice. Behav Neurosci 121, 12031214.

[42] Porras-García E, Cendelin J, Domínguez-del-Toro E, Vožeh F, Delgado-García JM (2005) Purkinje cell loss affects differentially the execution, acquisition and prepulse inhibition of skeletal and facial motor responses in Lurcher mice. Eur J Neurosci 21, 979-988.

[43] Paxinos G, Franklin KBJ (2001) The mouse Brain in Sterotaxic Coordinates, 2nd edn., Academic Press, Sydney.

[44] Domínguez-del-Toro E, Rodríguez-Moreno A, Porras-García E, Sánchez-Campusano R, Blanchard V, Lavilla M, Böhme GA, Benavides J, Delgado-García JM (2004) An in vitro and in vivo study of early deficits in associative learning in transgenic mice that over-express a mutant form of human APP associated with Alzheimer's disease. Eur J Neurosci 20, 1945-1952.

[45] Gruart A, Muñoz MD, Delgado-García JM (2006) Involvement of the CA3-CA1 synapse in the acquisition of associative learning in behaving mice. J Neurosci 26, 1077-1087.

[46] Zucker RS, Regehr WG (2002) Short-term synaptic plasticity. Annu Rev Physiol 64, 355-405.

[47] Gureviciene I, Ikonen S, Gurevicius K, Sarkaki A, van Groen T, Pussinen R, Ylinen A, Tanila H (2004) Normal induction but accelerated decay of LTP in APP + PS1 transgenic mice. Neurobiol Dis 15, 188-195.

[48] Bliss TVP, Gardner-Medwin AR (1973) Long-lasting potentiation of synaptic transmission in the dentate area of the unanaesthetized rabbit following stimulation of the perforant path. J Physiol (Lond) 232, 357-374.

[49] Sebastià J, Cristòfol R, Pertusa M, Vílchez D, Torán N, Barambio S, Rodríguez-Farré E, Sanfeliu C (2004) Down's syndrome astrocytes have greater antioxidant capacity than euploid astrocytes. Eur J Neurosci 20, 2355-2366.

[50] Rahman I, Kode A, Biswas, SK (2006) Assay for quantitative determination of glutathione and glutathione disulfide levels using enzymatic recycling method. Nat Protocols 1, 31593165 .

[51] Giménez-Llort L, Oghagbon EK, Cañete T, Bosch A (2008) Glucose homeostasis in triple-transgenic $3 \times \mathrm{Tg}-\mathrm{AD}$ mice is disrupted at early stages of the disease. Alzheimers Dement 4 T689-T690.

[52] Fewlass DC, Noboa K, Pi-Sunyer FX, Johnston JM, Yan SD, Tezapsidis N (2004) Obesity-related leptin regulates Alzheimer's Abeta. FASEB J 18, 1870-1878.

[53] Greco SJ, Bryan KJ, Sarkar S, Zhu X, Smith MA, Ashford JW, Johnston JM, Tezapsidis N, Casadesus G (2010) Leptin reduces pathology and improves memory in a transgenic mouse model of Alzheimer's disease. J Alzheimers Dis 19, 1157-1167.

[54] Leamy LJ, Pomp D, Lightfoot JT (2009) Genetic variation for body weight change in mice in response to physical exercise. BMC Genet 21, 10:58.

[55] Gruart A, López-Ramos JC, Muñoz MD, Delgado-García JM (2008) Aged wild-type and APP, PS1, and APP + PS1 mice present similar deficits in associative learning and synaptic plasticity independent of amyloid load. Neurobiol Dis 30, 439-450.

[56] Geyer MA (2006) The family of sensorimotor gating disorders: comorbidities or diagnostic overlaps? Neurotox Res 10, 211-220.

[57] Billings LM, Oddo S, Green KN, McGaugh JL, LaFerla FM (2005) Intraneuronal A $\beta$ causes the onset of early Alzheimer's disease-related cognitive deficits in transgenic mice. Neuron 45, 675-688.
[58] Parachikova A, Nichol KE, Cotman CW (2008) Short-term exercise in aged $\operatorname{Tg} 2576$ mice alters neuroinflammation and improves cognition. Neurobiol Dis 30, 121-129.

[59] Rampon C, Tang YP, Goodhouse J, Shimizu E, Kyin M, Tsien JZ (2000) Enrichment induces structural changes and recovery from nonspatial memory deficits in CA1 NMDAR1knockout mice. Nat Neurosci 3, 238-244.

[60] Balleine BW (2005) Neural bases of food-seeking: affect, arousal and reward in corticostriatolimbic circuits. Physiol Behav 86, 717-730.

[61] Blanchard J, Decorte L, Noguès X, Micheau J (2009) Characterization of cognition alteration across the course of the disease in APP751SL mice with parallel estimation of cerebral A $\beta$ deposition. Behav Brain Res 201, 147-157.

[62] Jacobsen JS, Wu CC, Redwine JM, Comery TA, Arias R, Bowlby M, Martone R, Morrison JH, Pangalos MN, Reinhart PH, Bloom FE (2006) Early-onset behavioral and synaptic deficits in a mouse model of Alzheimer's disease. Proc Natl Acad Sci U S A 103, 5161-5166.

[63] Nalbantoglu J, Tirado-Santiago G, Lahsaïni A, Poirier J, Goncalves O, Verge G, Momoli F, Welner SA, Massicotte G, Julien JP, Shapiro ML (1997) Impaired learning and LTP in mice expressing the carboxy terminus of the Alzheimer amyloid precursor protein. Nature 387, 500-505.

[64] Larson J, Lynch G, Games D, Seubert P (1999) Alterations in synaptic transmission and long-term potentiation in hippocampal slices from young and aged PDAPP mice. Brain Res 840, 23-35.

[65] Chapman PF, White GL, Jones MW, Cooper-Blacketer D, Marshall VJ, Irizarry M, Younkin L, Good MA, Bliss TV, Hyman BT, Younkin SG, Hsiao KK (1999) Impaired synaptic plasticity and learning in aged amyloid precursor protein transgenic mice. Nat Neurosci 2, 271-276.

[66] Gengler S, Hamilton A, Hölscher C (2010) Synaptic plasticity in the hippocampus of a APP/PS1 mouse model of Alzheimer's disease is impaired in old but not young mice. PLoS One 5, e9764.

[67] Takeda T, Hosohawa M, Higuchi K (1997) Senescenceaccelerated mice (SAMP): a novel murine model of senescence. Exp Gerontol 217, 37-40.

[68] Pallas M, Camins A, Smith MA, Perry G, Lee HG, Casadesus G (2008) From aging to Alzheimer's disease: unveiling "the switch" with the senescence-accelerated mouse model (SAMP8). J Alzheimers Dis 15, 615-624.

[69] Richards JG, Higgins GA, Ouagazzal AM, Ozmen L, Kew JN, Bohrmann B, Malherbe P, Brockhaus M, Loetscher H, Czech C, Huber G, Bluethmann H, Jacobsen H, Kemp JA (2003) PS2APP transgenic mice, coexpressing hPS2mut and hAPPswe, show age-related cognitive deficits associated with discrete brain amyloid deposition and inflammation. $J \mathrm{Neu}$ rosci 23, 8989-9003.

[70] Oddo S, Caccamo A, Cheng D, Jouleh B, Torp R, LaFerla FM (2007) Genetically augmenting tau levels does not modulate the onset or progression of $A \beta$ pathology in transgenic mice. J Neurochem 102, 1053-1063.

[71] Mastrangelo MA, Bowers WJ (2008) Detailed immunohistochemical characterization of temporal and spatial progression of Alzheimer's disease-related pathologies in male tripletransgenic mice. BMC Neurosci 9, 81.

[72] Adlard PA, Perreau VM, Pop V, Cotman CW (2005) Voluntary exercise decreases amyloid load in a transgenic model of Alzheimer's disease. J Neurosci 25, 4217-4221.

[73] Mirochnic S, Wolf S, Staufenbiel M, Kempermann G (2009) Age effects on the regulation of adult hippocampal neurogen- 
esis by physical activity and environmental enrichment in the APP23 mouse model of Alzheimer disease. Hippocampus 19, 1008-1018.

[74] Richter H, Ambrée O, Lewejohann L, Herring A, Keyvani K, Paulus W, Palme R, Touma C, Schäbitz WR, Sachser N (2008) Wheel-running in a transgenic mouse model of Alzheimer's disease: protection or symptom? Behav Brain Res 190, 74-84.

[75] Nichol KE, Poon WW, Parachikova AI, Cribbs DH, Glabe CG, Cotman CW (2008) Exercise alters the immune profile in Tg2576 Alzheimer mice toward a response coincident with improved cognitive performance and decreased amyloid. $J$ Neuroinflammation 5, 13.

[76] Resende R, Moreira PI, Proença T, Deshpande A, Busciglio J, Pereira C, Oliveira CR (2008) Brain oxidative stress in a tripletransgenic mouse model of Alzheimer disease. Free Radic Biol Med 44, 2051-2057.
[77] Borrás C, Gambini J, López-Grueso R, Pallardó FV, Viña J (2010) Direct antioxidant and protective effect of estradiol on isolated mitochondria. Biochim Biophys Acta 1802 205-211.

[78] Arshavsky YI (2010) Why Alzheimer's disease starts with a memory impairment: neurophysiological insight. $J$ Alzheimers Dis 20, 5-16.

[79] Caraci F, Copani A, Nicoletti F, Drago F (2010) Depression and Alzheimer's disease: neurobiological links and common pharmacological targets. Eur J Pharmacol 626, 64-71.

[80] Guimarães HC, Levy R, Teixeira AL, Beato RG, Caramelli P (2008) Neurobiology of apathy in Alzheimer's disease. Arq Neuropsiquiatr 66, 436-443.

[81] Castellani RJ, Lee HG, Zhu X, Perry G, Smith MA (2008) Alzheimer disease pathology as a host response. $\mathrm{J} \mathrm{Neu}$ ropathol Exp Neurol 67, 523-531. 